TITLE:

\title{
New Bedform Phase Diagrams and Discriminant Functions for Formative Conditions of Bedforms in Open-Channel Flows
}

\section{$\operatorname{AUTHOR}(\mathrm{S}):$}

Ohata, Koji; Naruse, Hajime; Yokokawa, Miwa; Viparelli, Enrica

\section{CITATION:}

Ohata, Koji ...[et al]. New Bedform Phase Diagrams and Discriminant Functions for Formative Conditions of Bedforms in Open-Channel Flows. Journal of Geophysical Research: Earth Surface 2017, 122(11): 2139-2158

ISSUE DATE:

2017-11

URL:

http://hdl.handle.net/2433/228345

\section{RIGHT:}

(C)2017. American Geophysical Union.; The full-text file will be made open to the public on 14 June 2018 in accordance with publisher's 'Terms and Conditions for Self-Archiving'. 


\section{Journal of Geophysical Research: Earth Surface}

\author{
RESEARCH ARTICLE \\ 10.1002/2017JF004290 \\ Key Points: \\ - New bedform phase diagrams \\ with three dimensionless axes are \\ presented \\ - Quantitative threshold conditions \\ of bedforms were obtained as \\ polynomial functions on the basis of \\ new three-dimensional diagrams \\ - The paleoflow velocity of the \\ back wash flow of a tsunami was \\ reconstructed using our discriminant \\ functions
}

Supporting Information:

- Supporting Information S1

- Table S1

- Table S2

- Data Set S1

- Movie S1

- Movie S2

Correspondence to:

K. Ohata,

ohata.koji.24z@st.kyoto-u.ac.jp

Citation:

Ohata, K., Naruse, H., Yokokawa, M., \& Viparelli, E. (2017). New bedform phase diagrams and discriminant functions for formative conditions of bedforms in open-channel flows. Journal of Geophysical Research Earth Surface, 122, 2139-2158. https://doi.org/10.1002/2017JF004290

Received 17 MAR 2017 Accepted 24 SEP 2017 Accepted article online 30 SEP 2017 Published online 9 NOV 2017

(C)2017. American Geophysical Union. All Rights Reserved.

\section{New Bedform Phase Diagrams and Discriminant Functions for Formative Conditions of Bedforms in Open-Channel Flows}

\author{
Koji Ohata1 ${ }^{1}$, Hajime Naruse1 ${ }^{1}$, Miwa Yokokawa², and Enrica Viparelli3 ${ }^{3}$ \\ ${ }^{1}$ Department of Geology and Mineralogy, Division of Earth and Planetary Sciences, Graduate School of Science, Kyoto \\ University, Kyoto, Japan, ${ }^{2}$ Faculty of Information Science and Technology, Osaka Institute of Technology, Osaka, Japan, \\ ${ }^{3}$ Department of Civil and Environmental Engineering, University of South Carolina, Columbia, SC, USA
}

\begin{abstract}
Understanding of the formative conditions of fluvial bedforms is significant for both river management and geological studies. Diagrams showing bedform stability conditions have been widely used for the analyses of sedimentary structures. However, the use of discriminants to determine the boundaries of different bedforms regimes has not yet been explored. In this study, we use discriminant functions to describe formative conditions for a range of fluvial bedforms in a 3-D dimensionless parametric space. We do this by means of discriminant analysis using the Mahalanobis distance. We analyzed 3,793 available laboratory and field data and used these to produce new bedform phase diagrams. These diagrams employ three dimensionless parameters representing properties of flow hydraulics and sediment particles as their axes. The discriminant functions for bedform regimes proposed herein are quadratic functions of three dimensionless parameters and are expressed as curved surfaces in 3-D space. These empirical functions can be used to estimate paleoflow velocities from sedimentary structures. As an example of the reconstruction of hydraulic conditions, we calculated the paleoflow velocity of the 2011 Tohoku-Oki tsunami backwash flow from the sedimentary structures of the tsunami deposit. In so doing, we successfully reconstructed reasonable values of the paleoflow velocities.
\end{abstract}

\section{Introduction}

Bedforms are topographic features formed by interactions between flow and sediment transport. For example, ripples and dunes form under subcritical flows, that is, flows with a Froude number smaller than unity and frequently observed on the bottom of river channels (Bridge \& Demicco, 2008). It has also been observed that turbidity currents commonly form bedforms migrating upstream on the floor of the deep sea (Hughes Clarke, 2016). In general, bedform heights and lengths range from several millimeters to hundreds of meters. Bedforms are classified into several types according to their configuration or size. The presence of bedforms on a channel bed affects flow resistance via the form drag, so that the prediction of bedform formation and characteristics, especially dunes, is useful for river management (Best, 2005). Different ranges of flow conditions and sediment grain size result in the formation of bedforms with different characteristics, that is, bedform phases or bed phases (in the sense of Southard, 1991). Bedform phase diagrams for unidirectional flows have been proposed on the basis of laboratory and field observations (e.g., Chaubert \& Chauvin, 1963; Simons \& Richardson, 1966; Southard \& Boguchwal, 1990; van den Berg \& van Gelder, 1993) to describe conditions for equilibrium bedform phase. It is important to mention here that bedform phase diagrams have been produced also for oscillating (wave) flows and combined wave-current flows (e.g., Dumas et al., 2005; Kleinhans, 2005b; Perillo et al., 2014).

Understanding the bedform formative conditions is also important for geological studies. Bedforms are preserved as sedimentary structures in strata, and hence, they are clues to the reconstruction of paleoflow conditions. Downstream dipping cross lamination is produced by undulating downstream migrating bedforms such as ripples and dunes, and parallel lamination is formed by plane beds (Bridge \& Best, 1988). Antidunes produce lenticular lamina sets with concave upward erosional bases (Alexander et al., 2001; Yokokawa et al., 2010). The presence of bedforms can be identified in the geologic records, for example, in outcrops, and diagrams for equilibrium bedform phase can be used in the analysis of sedimentary structures 
to reconstruct paleoflow conditions (e.g., Baas et al., 2000). In other words, when the bedform type is identified from sedimentary structures in geologic sections, bedform phase diagrams can be used to infer a range of paleoflow velocities based on the bedform formative conditions. In addition, an observed transition of primary sedimentary structure in strata suggests that flow conditions likely changed during deposition. Thus, the paleohydraulic condition at the transition between sedimentary structures can be estimated from the threshold conditions of bedform phases in question. Applications of bedform phase diagrams are not limited to the analysis of sedimentary structures in fluvial deposits. They have been applied to deposits formed in various environments such as turbidites (e.g., Baas et al., 2000), megaflooding from glacial lakes (e.g., Alho et al., 2010), tidal deposits (e.g., Mitchell et al., 2010), and tsunami deposits (Fujiwara \& Tanigawa, 2014). Diagrams employing dimensionless parameters are also applicable to extraterrestrial environments such as Mars (Kleinhans, 2005a).

In recent years, research has focused on the understanding of bedforms of unconventional type. For instance, Yokokawa, Takahashi, et al. (2011) and Cartigny et al. (2014) compiled data from laboratory experiments of Froude (Fr) supercritical flows conducted by themselves and other researchers (e.g., Yokokawa et al., 2010). They produced bedform phase diagrams showing Fr supercritical regimes such as cyclic steps, which had not been included in previous bedform phase diagrams (e.g., Southard \& Boguchwal, 1990). Furthermore, Baas et al. $(2009,2013)$ focused on the effect of cohesive materials on the formation of bedforms, and Baas et al. (2016) proposed a new phase diagram for bedforms which consist of sand-mud mixtures. These recent endeavors imply that more comprehensive diagrams are needed to understand the full range of bedform development, which presumably requires extension of conventional 2-D diagrams into at least 3-D alternatives.

In spite of their significance in analyses of sedimentary structures, boundaries of bedform regime in bedform phase diagrams have tended to be drawn arbitrarily and were rarely examined quantitatively using the robust inferential methodologies. In addition, the majority of studies have employed only two parameters for their diagrams, despite the fact that it has been shown that the formative conditions for equilibrium bedforms are governed by at least three dimensionless parameters (Southard \& Boguchwal, 1990; Garcia, 2008). These dimensional analyses indicate that the threshold conditions between bedform phases should be (hyper) surfaces in dimensionless parametric space, not 2-D lines. In several previous studies, however, the threshold conditions between bedform phases were defined as functions of one or two variable(s) (e.g., van den Berg \& van Gelder, 1993; Vanoni, 1974).

In addition to the visual expression obtained by bedform phase diagrams, quantitative examination of the threshold conditions of bedform phase can contribute to our understanding of the physical mechanisms of bedform formation. For example, Izumi and Parker (2009) developed a theory for the weakly nonlinear stability analysis of bedforms, which predicts hysteresis in transition between upstream migrating antidunes and upper plane beds. Their theory is supported by the fact that these bedforms are observed in regions which at least partially overlap with theoretical predictions.

Here we present novel three-dimensional bedform phase diagrams in which the boundaries between bedform phases are determined using discriminant analysis. Discriminant analysis is a statistical method to determine a function to categorize a set of parameters on the basis of given categorized sets of variables, the discriminant function. Our discriminant functions were derived on the basis of dimensionless parameters computed from hydraulic data for unidirectional open-channel flows. For simplicity, we employed data for only equilibrium bedforms consisting of cohesionless siliciclastic particles. Bedforms formed by combined flows or waves were excluded. In particular, we used 3,438 available laboratory data and 355 available field data. Two sets of dimensionless parameters are employed to define discriminators for equilibrium bedform phase. The first set contains dimensionless particle diameter, the Shields parameter, and Froude number, and the second set contains dimensionless particle diameter, dimensionless flow velocity, and dimensionless flow depth. We applied the method of discriminant analysis using the Mahalanobis distance (de Maesschalck et al., 2000), which permits non-Gaussian data distribution. Although it is somewhat difficult to visualize the threshold conditions for bedforms in the new 3-D bedform phase diagrams (because the typical visualization first involves projection onto a plane), our discriminant analysis provides a simple quadratic polynomial function of three dimensionless variables to calculate the threshold conditions for bedform phase. These are expressed as curved surfaces in the 3-D diagrams. The discriminant functions obtained in this study allow us to estimate 
paleoflow velocities from sedimentary structures in strata. We tested our method by reconstructing a backwash flow velocity from a tsunami deposit. Reasonable estimates of the flow conditions were obtained from our analysis.

\section{Methodology}

\subsection{Governing Parameters}

Open-channel flow bedforms depend on several parameters that reflect the properties of flows and sediment grains. Southard and Boguchwal (1990) stated that seven dimensional parameters, including flow velocity, sediment size, and fluid density characterize the bed state. With the aid of dimensional analysis the number of parameters characterizing the bedform states can be reduced to four nondimensional parameters. Two parameters represent the flow conditions, one the sediment size, and one the density difference between the sediment and the ambient fluid (Garcia, 2008). Bedform phase regimes can be thus expressed in the space of these dimensionless parameters (e.g., van den Berg \& van Gelder, 1993; Chaubert \& Chauvin, 1963). In this study, three dimensionless parameters describing hydraulic conditions and sediment properties are considered. The density difference between sediment and water was not in the analysis because it was nearly constant (1.65 for submerged specific gravity) among all experiments and field observations.

The 2-D diagram proposed by Chaubert and Chauvin (1963) describes bedform phase regimes in lower regime (lower plane beds, ripples, and dunes) using the Shields number $\tau_{*}$ and the shear Reynolds number $R e_{*}$. These dimensionless parameters are defined respectively as

$$
\begin{aligned}
\tau_{*} & =\frac{u_{*}^{2}}{R g D_{50}} \\
R e_{*} & =\frac{u_{*} D_{50}}{v}
\end{aligned}
$$

where $u_{*}$ is the shear velocity, defined as $u_{*}=\sqrt{g h S}$, and $R$ is the submerged specific gravity of the sediment, defined as $R=\left(\rho_{\mathrm{s}}-\rho_{\mathrm{f}}\right) / \rho_{\mathrm{f}}$ with $\rho_{\mathrm{f}}$ and $\rho_{\mathrm{s}}$ respectively denoting the fluid and sediment densities; $g$ is the acceleration of gravity, $h$ is the flow depth, and $S$ is the bed slope. In addition, $D_{50}$ denotes the median diameter of the sediment, and $v$ denotes the kinematic viscosity of water. Chaubert and Chauvin diagram also shows the relationship between bedforms and the dimensionless particle diameter $D_{*}$, where $D_{*}$ is defined by Bonnefille (1963) as follows:

$$
D_{*}=D_{50}\left(\frac{R g}{v^{2}}\right)^{\frac{1}{3}}
$$

Vanoni (1974) used the Froude number $F r$ and the relative flow depth $h / D_{50}$ as metrics of hydraulics and the ratio of $R e_{\mathrm{p}}$ to $R^{\frac{1}{2}}$ as the property of sediment particles. The Froude number is defined as

$$
F r=\frac{U}{\sqrt{g h}}
$$

where $U$ is the depth averaged flow velocity. The particle Reynolds number $R e_{p}$ is defined as

$$
R e_{\mathrm{p}}=\frac{\sqrt{R g D_{50}} D_{50}}{v}
$$

The diagram produced by van den Berg and van Gelder (1993) employed the dimensionless particle diameter $D_{*}$ and a mobility parameter $\theta^{\prime}$, defined as

$$
\theta^{\prime}=\frac{U^{2}}{g R D_{50} C^{\prime 2}}
$$

with

$$
C^{\prime}=18 \log \frac{4 h}{D_{90}}
$$

in which $C^{\prime}$ is the dimensionless Chézy coefficient related to grain roughness and $D_{90}$ is the grain size such that $90 \%$ of the bed material is finer. Their diagram was extended to supercritical flow regime by Cartigny et al. (2014) and to bedforms which contain cohesive clay particles by Baas et al. (2016). 
Southard and Boguchwal (1990) stated that the following four parameters characterize bedform type: dimensionless sediment size $D^{0}$, dimensionless flow velocity $U^{0}$, dimensionless flow depth $h^{0}$, and density ratio $\rho_{\mathrm{s}} / \rho_{\mathrm{f}}$. The three dimensionless parameters above are respectively defined as

$$
\begin{aligned}
& D^{0}=D_{50}\left(\frac{\rho_{\mathrm{f}} \gamma^{\prime}}{\mu^{2}}\right)^{\frac{1}{3}}=D_{50}\left(\frac{R g}{v^{2}}\right)^{\frac{1}{3}} \\
& U^{0}=U\left(\frac{\rho_{\mathrm{f}}^{2}}{\mu \gamma^{\prime}}\right)^{\frac{1}{3}}=U\left(\frac{1}{v R g}\right)^{\frac{1}{3}} \\
& h^{0}=h\left(\frac{\rho_{\mathrm{f}} \gamma^{\prime}}{\mu^{2}}\right)^{\frac{1}{3}}=h\left(\frac{R g}{v^{2}}\right)^{\frac{1}{3}}
\end{aligned}
$$

where $\mu$ denotes fluid viscosity and $\gamma^{\prime}$ denotes submerged sediment specific weight. However, they used a temperature of $10^{\circ} \mathrm{C}$ as a reference temperature and proposed $10^{\circ} \mathrm{C}$-equivalent depth-velocity-size diagram which can then be modified for application to other temperatures. It is seen from a comparison of equation (3) and the first of equation (8) that $D_{*}$ and $D^{0}$ are identical.

In the present study, we employ two sets of dimensionless parameters to describe the bedform phase regimes. The first set is $D_{*}-\tau_{*}-F r$, and the second set is $D^{0}-U^{0}-h^{0}$. The former set of dimensionless parameters $D_{*}-\tau_{*}-F r$ has an advantage in terms of the physical interpretation. For example, when $F r$ is high, the water surface may become unstable, and the resulting surface waves affect sediment transport and therefore can give rise to antidunes (Kennedy, 1963). In addition, Fr is convenient to distinguish Fr supercritical from subcritical flows. The disadvantage of using $\mathrm{Fr}$ and $\tau_{*}$ is that both parameters contain the flow depth; in other words they are not independent. This notwithstanding, here we employed $\mathrm{Fr}$ and $\tau_{*}$ as dimensionless metrics of flow depth and velocity, respectively. The latter set of dimensionless parameters $D^{0}-U^{0}-h^{0}$ contains the parameters $D_{50}, U$, and $h$ separately. Therefore, discriminant functions obtained in this parametric space become explicit functions of $D_{50}, U$, and $h$, which is convenient to intuitively grasp the bedform phase regimes.

\subsection{Data Processing Procedures}

We used 3,438 laboratory data and 355 field data, from the literature, to produce the new diagrams based on two sets of dimensionless parameters described above. The relevant references are summarized in supporting information Table S1, and the data are compiled in Table S2. In general, all bedforms in this study were assigned to the same class as in the original references without consideration of further subclassifications provided therein. For the purposes of this study, bedforms were classified into seven types: lower plane beds, ripples, dunes, transition, upper plane beds, antidunes, and cyclic steps. Definitions of these bedforms are as follows. Ripples and dunes are downstream migrating bedforms that have gentle slopes along their stoss sides and steep slopes along their lee sides. Dunes in large rivers commonly have low-angle lee sides (e.g., Best et al., 2001). Ripples do not deform the water surface, whereas dunes are out of phase with the water surface waves (Venditti, 2013). These two bedforms are also different in size, such that wavelengths and heights of dunes are larger than those of ripples (Allen, 1982). Here megaripples and sand waves are regarded as synonymous to dunes (Ashley, 1990). If the bedform length was larger than $0.6 \mathrm{~m}$ and the bedform type was not described in the literature, the bedform in question was classified as dunes. Plane beds are characterized by nearly flat topography and are subclassified into two types: lower plane beds and upper plane beds. According to Bridge and Demicco (2008), lower plane beds are formed at around the threshold condition for the inception of sediment particle movement, and upper plane beds occur as the bed shear stress is increased well above the threshold of motion. Antidunes and cyclic steps are observed under Fr supercritical flow conditions (Cartigny et al., 2014). Antidunes are in phase with water surface waves, and they may migrate either upstream or downstream (Fukuoka et al., 1982). Although antidunes can be subclassified into several types such as nonbreaking antidunes (standing waves) and breaking antidunes (Cartigny et al., 2014; Fukuoka et al., 1982; Guy et al., 1966; Yokokawa, Takahashi, et al., 2011), this study regards these subdivisions collectively as a single type of bedforms. Cyclic steps are defined as a series of slowly upstream migrating steps (Cartigny et al., 2014; Parker \& Izumi, 2000). The flow rapidly accelerates on the lee side of the cyclic step, and a hydraulic jump occurs near the boundary between the stoss and lee sides. Chutes and pools have similar features to cyclic steps (Simons et al., 1965), so that they are regarded as synonymous to cyclic steps.

The ranges of basic variables are as follows. Median particle diameters, flume width, and flow depth of laboratory data range from $11 \mu \mathrm{m}$ to $23 \mathrm{~mm}, 0.02$ to $4 \mathrm{~m}$, and $1.2 \mathrm{~mm}$ to $0.91 \mathrm{~m}$, respectively. The corresponding 
Table 1

Number of Data Points for Each Bedform Type and P Values Calculated Using the Method of Mardia (1970)

\begin{tabular}{lccc}
\multirow{2}{*}{$\begin{array}{l}\text { Bedform } \\
\text { type }\end{array}$} & $\begin{array}{c}\text { Data } \\
\text { points }\end{array}$ & $\log _{10} D_{*}-\log _{10} \tau_{*}-\log _{10} F r$ & $\log _{10} D^{0}-\log _{10} U^{0}-\log _{10} h^{0}$ \\
\hline $\mathrm{L}$ & 94 & 0 & 0.15420 \\
$\mathrm{R}$ & 729 & 0 & 0 \\
$\mathrm{D}$ & 1,487 & 0 & 0 \\
$\mathrm{~T}$ & 326 & 0 & 0 \\
$\mathrm{U}$ & 701 & 0 & 0 \\
$\mathrm{~A}$ & 420 & 0.013904 & 0.035377 \\
$\mathrm{C}$ & 36 & 0.078464 & 0.031336 \\
R\&D & 2,216 & 0 & 0 \\
U\&A & 1,121 & 0 & 0 \\
T\&U & 1,027 & 0 & 0 \\
\hline
\end{tabular}

Note. The null hypothesis tested in this analysis is that the data are distributed according to the Gaussian data distribution. L: lower plane beds, R: ripples, D: dunes, T: transition, U: upper plane beds, A: antidunes, C: cyclic steps.

ranges of field data range from $18 \mu \mathrm{m}$ to $7 \mathrm{~mm}$, from 3.2 to $1136 \mathrm{~m}$, and from 0.2 to $26 \mathrm{~m}$. The flow velocity for the laboratory data ranges from 0.058 to $2.34 \mathrm{~m} / \mathrm{s}$, and that for the field data ranges from 0.31 to $3.75 \mathrm{~m} / \mathrm{s}$. In the same way as van den Berg and van Gelder (1993), $v$ is assumed to be a function of temperature according to the relation for clear fresh water:

$$
v=\left[1.14-0.031(T-15)+0.00068(T-15)^{2}\right] 10^{-6}
$$

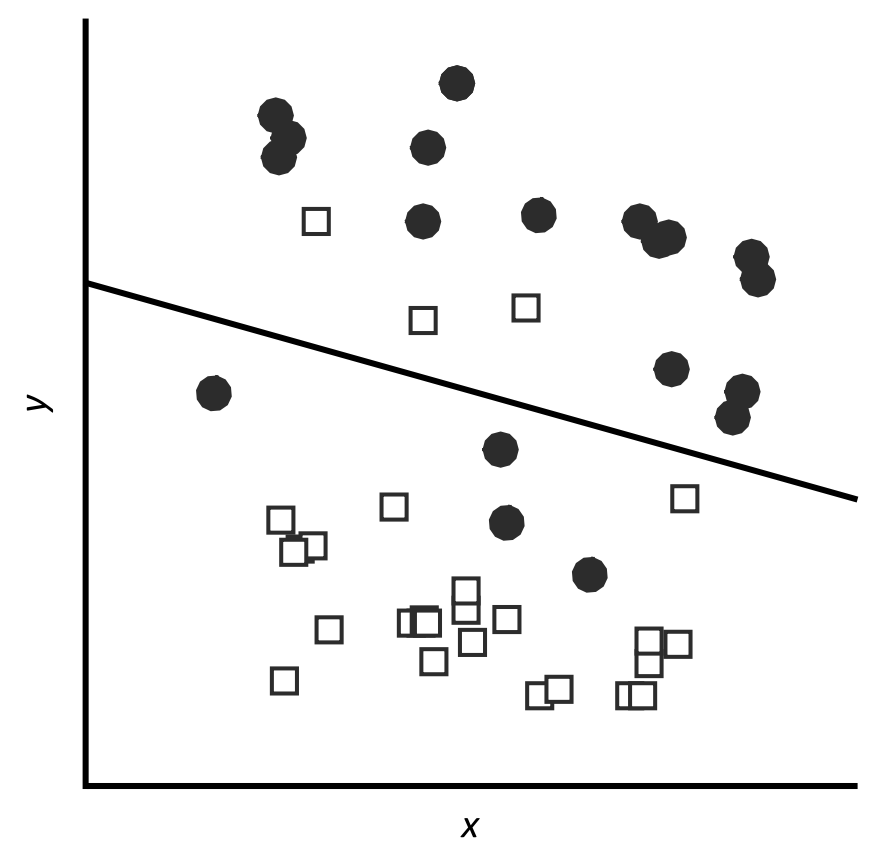

Figure 1. Conceptual diagram of the apparent error rate. Black circles and white squares denote different types of bedforms. The solid line, which indicates the discriminant function $f(x, y)=0$, divides parametric space into regions dominated by black circles and white squares. The squares above the solid line and the circles below the solid line are misclassified. The ratio of the number of misclassified data points to the total number of data points is the apparent error rate. where $T$ is temperature in degrees Celsius. A value of $20^{\circ} \mathrm{C}$ was assumed for data whose water temperature was not reported. The water temperature $T$ for the laboratory and field data ranged from 1.67 to $65.56^{\circ} \mathrm{C}$ and from 1.1 to $31.5^{\circ} \mathrm{C}$, respectively. The submerged specific gravity $R$ ranged from 1.61 to 1.7 in the laboratory data. The corresponding value for all the field data was assumed to be equal to 1.65 (the value for quartz). Laboratory flumes have smooth side walls and a rough bed which consists of sediment grains, so that shear stress on the side wall differs from that on the bed. Hence, the method of Chiew and Parker (1994) has been applied to remove the influence of side walls in determining bed shear stress for the experimental data. We have thus accounted for the side wall effect in computing the Shields mobility number $\tau_{\mathrm{b}}^{*}$ based on the bed shear stress (see Appendix A for details). Hereafter, we use the symbol $\tau_{*}$ for both $\tau_{*}$ and $\tau_{\mathrm{b}}^{*}$ for convenience. Moreover, the hydraulic conditions related to the formation of bedforms range very widely, and it was difficult to produce discriminant functions of bedform phases in linear parametric space. Therefore, we employed log-transformed parameters to obtain the discriminant functions.

\subsection{Discriminant Analysis}

We applied the method of discriminant analysis to identify the threshold conditions for bedform phase. Discriminant analysis is a statistical method of the supervised classification, which determines a function to categorize a set of parameters on the basis of given categorized sets of variables. Some classification methods (e.g., linear discriminant analysis, Fisher, 1936) assume that the variables of each data group follow normal distributions. Therefore, data were subjected to normality tests prior to 

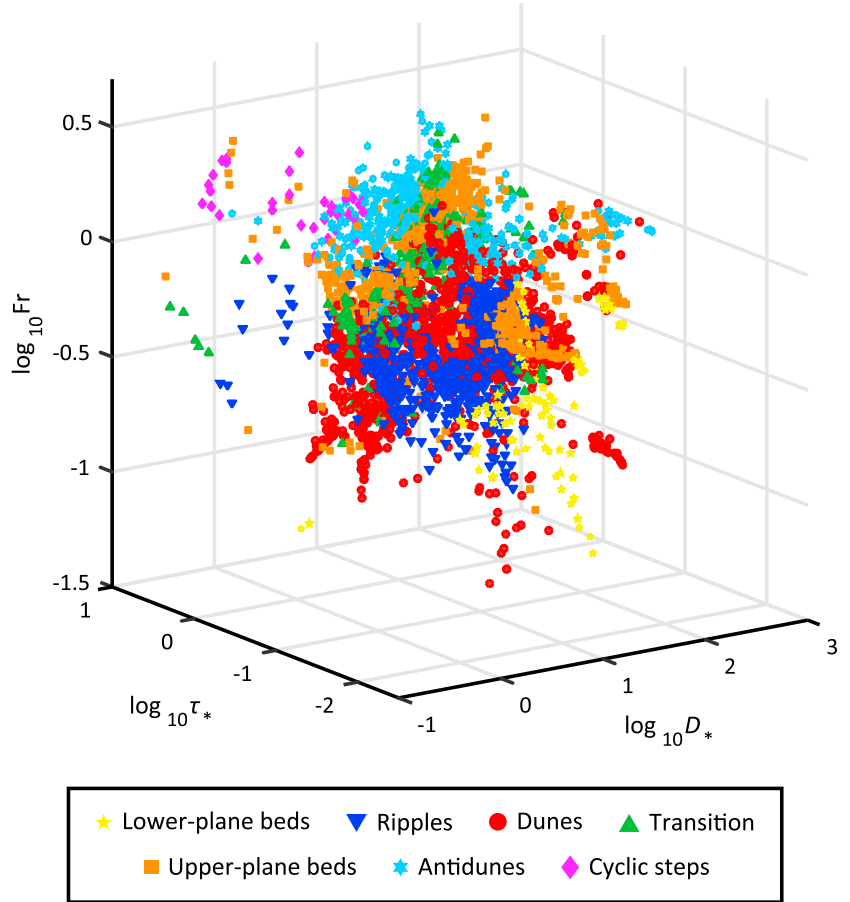

Figure 2. Three-dimensional phase diagram as a $\log _{10} D_{*}-\log _{10} \tau_{*}-\log _{10} \mathrm{Fr}$ cube. For convenience, we use the axis label $\log _{10} \tau_{*}$ for both experimental and field data. analysis to select the most appropriate classification method. The parametric space in this study consists of multivariables; as such the method of Mardia (1970) was used. We tested distributions of parameters categorized into bedform type as follows: lower plane beds $(L)$, ripples $(R)$, dunes $(D)$, transition $(T)$, upper plane beds $(U)$, antidunes $(A)$, cyclic steps $(C)$, lower regime bedforms (ripples and dunes: $R \& D$ ), upper regime bedforms (upper plane beds and antidunes: U\&A), and transition and upper plane beds (T\&U). The categories R\&D and U\&A were tested in order to compare our discriminant functions with those of Karim (1995).

The results of the normality test were not significant for most groups of variables at the $5 \%$ level (Table 1 ). In other words, we could not accept the null hypothesis that the data were normally distributed, indicating that nonparametric discriminant analysis is appropriate herein. Thus, the classification method using the Mahalanobis distance (de Maesschalck et al., 2000), which does not make assumptions on the shape of distributions, was adopted to obtain the boundaries of bedform phase regimes. The Mahalanobis distance is the distance between a data point and a categorized group of data points in parametric space, defined as follows:

$$
D_{M}(\mathbf{x})=\sqrt{(\mathbf{x}-\boldsymbol{\mu})^{\prime} \Sigma^{-1}(\mathbf{x}-\boldsymbol{\mu})}
$$

in which $\boldsymbol{\mu}$ denotes the mean vector of a group and $\Sigma$ denotes the covariance matrix. Using the Mahalanobis distance, this method assigns a data point to the group that shows the shortest distance among all categorized groups. In other words, a data point showing equivalent distances to two different groups can be regarded as a point on a boundary between two groups. Hence, the discriminant function which classifies data points to group A and group B is derived by solving the following equation:

$$
D_{\mathrm{M}}^{\mathrm{A}}(\mathbf{x})=D_{\mathrm{M}}^{\mathrm{B}}(\mathbf{x})
$$

where $D_{M}^{\mathrm{A}}$ and $D_{\mathrm{M}}^{\mathrm{B}}$ are the Mahalanobis distances from $\mathbf{x}$ to groups $\mathrm{A}$ and $\mathrm{B}$, respectively. The discriminant functions are inevitably quadratic polynomials because the Mahalanobis distance of an observation $\mathbf{x}$ is expressed as $\mathbf{x}$ squared.

In this study, the parameter $\boldsymbol{\mu}$ for each bedform type consists of three dimensionless parameters, that is, $D_{*}-\tau_{*}-F r$ or $D^{0}-U^{0}-h^{0}$. As a result, discriminant functions were derived as quadratic surfaces for specific pairs of bedform types, as defined later. Two kinds of error rates of each function were calculated to evaluate the reliability of the discriminant functions. One is the apparent error rate $E_{\mathrm{App}}$, which is the observed inaccuracy of the fitted model applied to the original data points (Efron, 1986). Figure 1 is a conceptual diagram of the apparent error rate. The other error rate is the result of leave-one-out cross-validation $E_{\mathrm{LOO}}$ (Kohavi, 1995). Leave-one-out cross validation is a method to estimate prediction error (Hastie et al., 2009). In this validation method, one data point is chosen as the validation data, and the other points are chosen as the training data. Discriminant analysis is conducted with the training data, and the performance of the resulting function is then tested against the validation data. This procedure is repeated, and the prediction error rate is eventually obtained from the ratio of misclassification of the validation data to the total number of data points.

\section{Results}

\subsection{Three-Dimensional Bedform Phase Diagram}

This study resulted in new bedform phase diagrams in which three dimensionless parameters are employed as axes of 3-D diagrams (Figures 2 and 4). Figures 2 and 4 show diagrams using $\log _{10} D_{*}-\log _{10} \tau_{*}-\log _{10} F r$ axes and $\log _{10} D^{0}-\log _{10} U^{0}-\log _{10} h^{0}$ axes, respectively. In addition, 2-D diagrams showing data projected on a plane of two dimensionless parametric space were also constructed (Figures 3 and 5).

\subsubsection{The $\log _{10} D_{*}-\log _{10} \tau_{*}-\log _{10}$ Fr Diagram}

Figure 2 shows the three-dimensional distribution of bedform phase regimes in the parametric space of $\log _{10} D_{*}-\log _{10} \tau_{*}-\log _{10} F r$. Figures $3 a-3 c$ are 2-D diagrams projected from the $\log _{10} F r, \log _{10} \tau_{*}$, and $\log _{10} D_{*}$ 

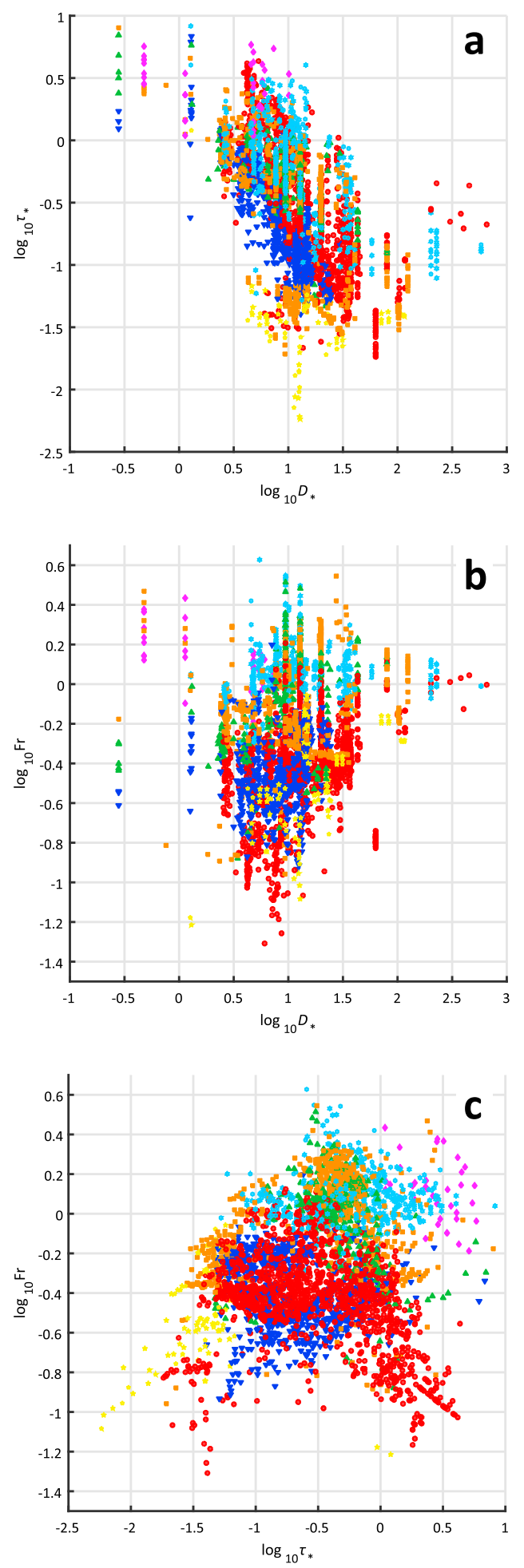

Lower-plane beds $\boldsymbol{\nabla}$ Ripples Dunes $\Delta$ Transition - Upper-plane beds * Antidunes Cyclic steps

Figure 3. New bedform phase diagrams projected onto (a) the $\log _{10} D_{*}-\log _{10} \tau_{*}$ plane, (b) the $\log _{10} D_{*}-\log _{10} \operatorname{Fr}$ plane, and (c) the $\log _{10} \tau_{*}-\log _{10}$ Fr plane. 


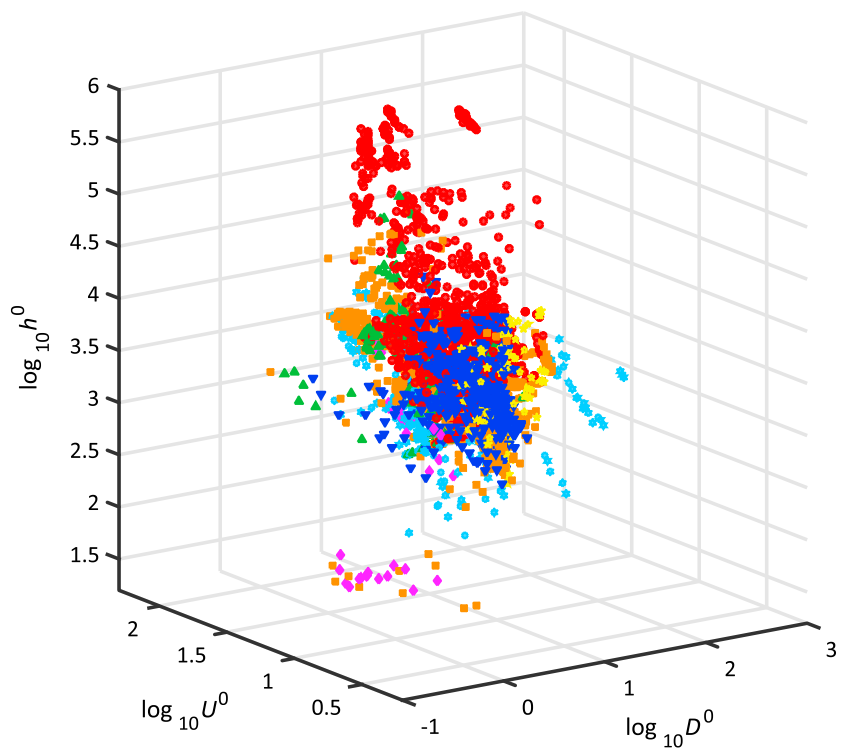

$$
\begin{gathered}
\text { Lower-plane beds } \nabla \text { Ripples Dunes } \Delta \text { Transition } \\
\square \text { Upper-plane beds } \quad \text { Antidunes } \diamond \text { Cyclic steps }
\end{gathered}
$$

Figure 4. Three-dimensional phase diagram as a $\log _{10} D^{0}-\log _{10} U^{0}-\log _{10} h^{0}$ cube. axis direction, respectively. Lower plane beds tend to occur for $\log _{10} \tau_{*}$ less than $-1\left(\tau_{*}<0.1\right)$ and for $\log _{10} D_{*}$ larger than $0.5\left(D_{*}>3.16\right)$ (Figures $3 a-3 c$ ). Lower plane beds do not form for $\log _{10} \mathrm{Fr}$ higher than 0 $\left(F r>1\right.$ ) (Figures $3 b$ and $3 c$ ). Ripples tend to occur for $\log _{10} F r$ less than -0.2 $(F r<0.63)$ (Figures $3 \mathrm{~b}$ and $3 \mathrm{c})$ and for $\log _{10} D_{*}$ less than $1.5\left(D_{*}<31.6\right)$ (Figures $3 \mathrm{a}$ and $3 \mathrm{~b}$ ) and form within a range of values of $\log _{10} \tau_{*}$ that is higher than that of lower plane beds (Figures $3 a$ and $3 c$ ). Dunes form in the field where either $\log _{10} F r$ or $\log _{10} D_{*}$ is higher than the range for ripples (Figures $3 a-3 c$ ). In addition, the range of values of $\log _{10} \tau_{*}$ in the dune region is about the same as that of ripple region (Figures $3 a$ and $3 c$ ). The transition region overlaps other regions and mainly extends between the dune region and upper plane bed region. Most transition data points exist in the field for which $\log _{10} F r$ is larger than $-0.4(F r>0.4)$ and $\log _{10} \tau_{*}$ is larger than $-0.5\left(\tau_{*}>0.32\right)$ (Figure $\left.3 c\right)$. Upper plane beds form for $\log _{10} F r$ larger than $-0.4(F r>0.4)$ (Figures $3 b$ and $3 c$ ). Many data points for upper plane beds plot in the field for which $\log _{10} \tau_{*}$ is larger than $-0.5\left(\tau_{*}>0.32\right)$, but some data points plot in the field for which $\log _{10} \tau_{*}$ is less than -1 $\left(\tau_{*}<0.1\right)$ and overlap the lower plane bed region (Figures $3 a$ and $3 c$ ). Antidunes data points plot such that $\log _{10} F r$ is above $-0.2(F r>0.63)$ and $\log _{10} \tau_{*}$ is above $-1\left(\tau_{*}>0.1\right)$ (Figures $\left.3 a-3 c\right)$. Some data points overlap the upper plane bed region and the transition region (Figures $3 a-3 c$ ). Cyclic steps tend to plot in the range where $\log _{10} \tau_{*}$ exceed approximately $0.2\left(\tau_{*}>1.58\right)$ (Figures $3 a$ and $3 c$ ). In addition, cyclic steps plot in a region for which $\log _{10} F r$ can be as high as 0 ( $F r \sim 1$ ) (Figures $3 \mathrm{~b}$ and $3 \mathrm{c}$ ). In the 2-D diagrams, the domain $0.5<\log _{10} D_{*}<1.5,-1<\log _{10} \tau_{*}<0$, and $-0.6<\log _{10} \mathrm{Fr}<0\left(3.16<D_{*}<31.6,0.1<\tau_{*}<1\right.$, and $\left.0.25<\mathrm{Fr}<1\right)$ contains several types of bedforms (Figure 3 ).

\subsubsection{The $\log _{10} D^{0}-\log _{10} U^{0}-\log _{10} h^{0}$ Diagram}

Figure 4 shows the three-dimensional distribution of bedform phase in the parametric space of $\log _{10} D^{0}-\log _{10} U^{0}-\log _{10} h^{0}$. Figures $5 a-5 c$ are 2-D diagrams projected from the $\log _{10} h^{0}, \log _{10} U^{0}$, and $\log _{10} D^{0}$ axis direction, respectively. Lower plane beds are found on a regime such that $\log _{10} h^{0}$ varies from 2.5 to 4 $\left(316 \leq h^{0} \leq 10^{4}\right.$ ) (Figures $5 \mathrm{~b}$ and $5 \mathrm{c}$ ). Further, lower plane beds form in the range for which $\log _{10} U^{0}$ is less than $1.5\left(U^{0}<31.6\right)$ (Figures $5 a$ and $\left.5 c\right)$. The ranges of $\log _{10} U^{0}$ and $\log _{10} h^{0}$ corresponding to the ripple region are nearly identical to those of lower plane beds (Figure $5 \mathrm{c}$ ). Figures $5 \mathrm{a}$ and $5 \mathrm{~b}$ show that ripples are found for $\log _{10} D^{0}$ less than about $1.2\left(D^{0}<15.8\right)$. The dune region extends into higher range of values of $\log _{10} U^{0}$ domain than the ripple region (Figures $5 \mathrm{a}$ and $5 \mathrm{c}$ ). The dune region lies between values of $\log _{10} h^{0}$ of 2.5 and about $5.6\left(316 \leq h^{0} \leq 398,110\right)$ (Figures $5 \mathrm{~b}$ and $5 \mathrm{c}$ ). The transition region overlaps other regions and mainly extends between dunes and upper plane beds region, as was the case for the $\log _{10} D_{*}-\log _{10} \tau_{*}-\log _{10} F r$ diagram (Figures 2 and 4). Upper plane beds mainly form in the field for which $\log _{10} U^{0}$ is larger than $1.2\left(U^{0}>15.8\right)$ (Figures $5 \mathrm{a}$ and $5 \mathrm{c}$ ). The range of values of $\log _{10} h^{0}$ in the upper plane bed region is as wide as that of the dune region (Figures $5 \mathrm{~b}$ and $5 \mathrm{c}$ ). Data points for antidunes are scattered around the domain $0.8<\log _{10} U^{0}<2.0$ and $1.5<\log _{10} h^{0}<4\left(6.3<U^{0}<100\right.$ and $\left.31.6<U^{0}<10^{4}\right)$ (Figures $5 \mathrm{a}-5 \mathrm{c}$ ). In particular, Figure $5 \mathrm{c}$ shows that the larger the $\log _{10} h^{0}$, the larger the $\log _{10} U^{0}$ needed to form antidunes. Cyclic steps form for conditions similar to those of antidunes (Figure $5 \mathrm{c}$ ). Additionally, the overlapping region between cyclic steps and other bedforms is clearer than the $\log _{10} D_{*}-\log _{10} \tau_{*}-\log _{10} \mathrm{Fr}$ diagram (Figures $3 \mathrm{C}$ and $5 \mathrm{C}$ ). In the 2-D diagrams, the domain $0.5<\log _{10} D^{0}<1.5,1.2<\log _{10} U^{0}<1.6$, and $3<\log _{10} h^{0}<4\left(3.16<D^{0}<31.6,15.8<U^{0}<39.8\right.$, and $10^{3}<D^{0}<10^{4}$ ) contains several kinds of bedforms (Figure 5).

\subsection{Discriminant Functions}

We have determined discriminant functions for the following boundaries: L-R, R-D, D-T, T-U, U-A, A-C, D-U, R\&D-T, T-U\&A , R\&D-T\&U, and T\&U-A. The discriminant functions take the form

$$
\alpha_{1} X^{2}+\alpha_{2} Y^{2}+\alpha_{3} Z^{2}+\alpha_{4} X Y+\alpha_{5} Y Z+\alpha_{6} X Z+\alpha_{7} X+\alpha_{8} Y+\alpha_{9} Z+\alpha_{10}=0
$$

where $X$ denotes $\log _{10} D_{*}$ or $\log _{10} D^{0}, Y$ denotes $\log _{10} \tau_{*}$ or $\log _{10} U^{0}$, and $Z$ denotes $\log _{10} F r$ or $\log _{10} h^{0}$. The coefficients of the discriminant functions $\alpha_{i}(i=1,2, \ldots, 10)$ are summarized in Tables 2 and 3 . Table 2 shows 

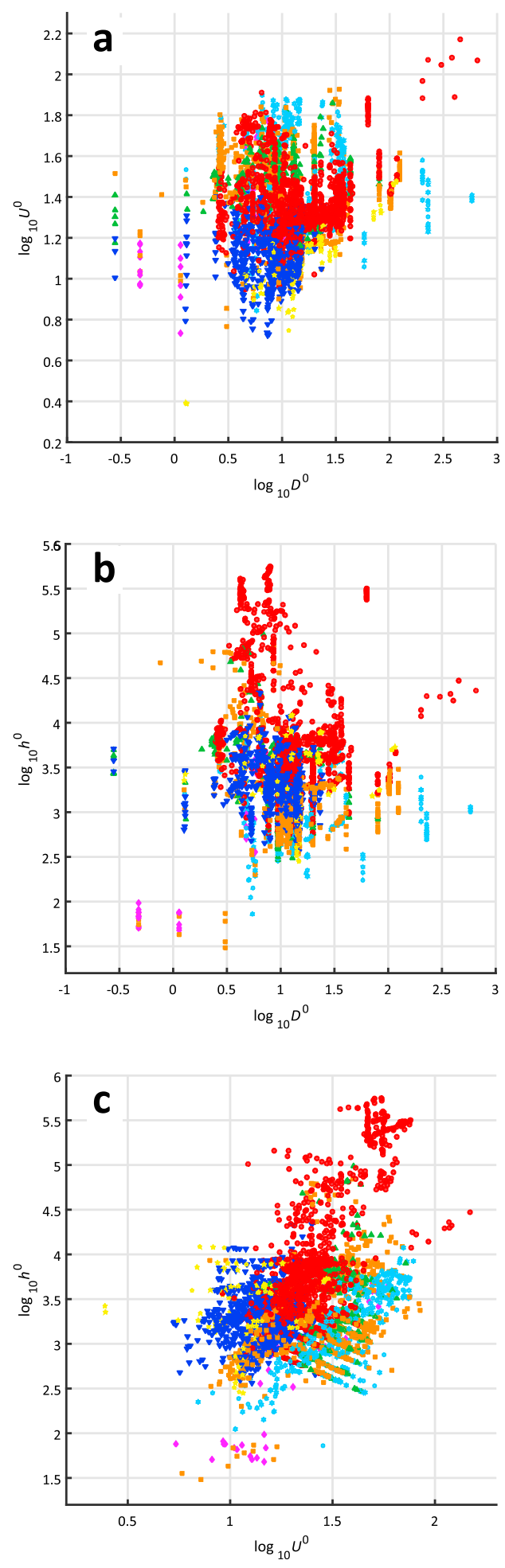

Lower-plane beds $\boldsymbol{\nabla}$ Ripples Dunes $\Delta$ Transition

- Upper-plane beds $\#$ Antidunes $\diamond$ Cyclic steps

Figure 5. New bedform phase diagrams projected onto (a) the $\log _{10} D^{0}-\log _{10} U^{0}$ plane, (b) the $\log _{10} D^{0}-\log _{10} h^{0}$ plane, and (c) the $\log _{10} U^{0}-\log _{10} h^{0}$ plane. 
Table 2

Coefficients of Discriminant Functions Expressed in Terms of $\log _{10} D_{*}-\log _{10} \tau_{*}-\log _{10}$ Fr Axes

\begin{tabular}{lcccccccccc}
\hline Boundary & $\alpha_{1}$ & $\alpha_{2}$ & $\alpha_{3}$ & $\alpha_{4}$ & $\alpha_{5}$ & $\alpha_{6}$ & $\alpha_{7}$ & $\alpha_{8}$ & $\alpha_{9}$ \\
\hline L-R & -45.852 & -16.41 & -11.665 & -58.652 & 6.921 & 16.673 & 49.523 & 47.742 & -17.481 \\
R-D & 40.217 & 19.455 & 20.114 & 51.264 & -21.183 & -32.735 & -42.358 & -22.774 & 30.391 & 13.428 \\
D-T & -0.81876 & -13.661 & -4.8051 & -9.6952 & 8.3125 & 11.423 & -6.3066 & 2.4187 & 6.7753 & 10.319 \\
T-U & 4.6385 & 13.976 & -2.8831 & 10.53 & 11.247 & 1.8652 & -6.2307 & -2.91 & 2.8736 & 2.3908 \\
U-A & 6.0004 & -2.7535 & -23.469 & 4.3836 & -19.219 & -23.388 & -6.7601 & -0.73867 & 26.841 & 1.7883 \\
A-C & -4.0227 & -28.199 & -83.101 & -15.33 & -96.017 & -65.101 & 12.178 & 46.627 & 86.111 & -14.026 \\
D-U & 3.8197 & 0.31551 & -7.6881 & 0.8349 & 19.559 & 13.288 & -12.537 & -0.49125 & 9.6489 & 12.71 \\
R\&D-T & -2.3063 & -13.887 & -1.6238 & -12.117 & 8.3288 & 10.841 & -1.5096 & 6.8203 & 9.4663 & 8.2113 \\
T-U\&A & 8.821 & 15.069 & -3.5122 & 15.634 & 8.2078 & -5.2503 & -11.783 & -6.1084 & 9.6981 & 4.4626 \\
R\&D-T\&U & 1.3729 & -0.64461 & -2.9068 & 2.5702 & 17.594 & 12.381 & -6.0229 & 4.7881 & 11.461 & 9.9712 \\
T\&U-A & 6.9596 & -2.0194 & -25.069 & 5.3665 & -17.237 & -23.063 & -8.4775 & -1.6164 & 27.72 & 2.4193 \\
\hline
\end{tabular}

Note. All abbreviations are as defined in Table 1.

the coefficients of the discriminant functions which use the set $\log _{10} D_{*}-\log _{10} \tau_{*}-\log _{10} F r$, and Table 3 shows the coefficients of discriminant functions which use the set $\log _{10} D^{0}-\log _{10} U^{0}-\log _{10} h^{0}$.

Table 4 shows the error rates for each function. In the region at the boundary between the transition regime to upper regime bedforms ( $T-U, U-A$, and T-U\&A), the apparent error rates are higher than $23 \%$ and up to $36 \%$. Meanwhile, the apparent error rates are lower than $19 \%$ in the region at the boundary between lower regime to the transition regime (R-D, D-T, and R\&D-T). Compared to the parameter $E_{\mathrm{LOO}}$ of the discriminant functions of the two dimensionless parameter sets, the discriminant functions in the parametric space $\log _{10} D_{*}-\log _{10} \tau_{*}-\log _{10} F r$ are more reliable for describing the boundaries of L-R, U-A, A-C, D-U, and T\&U-A. On the other hand, the discriminant functions in the parametric space $\log _{10} D^{0}-\log _{10} U^{0}-\log _{10} h^{0}$ are more reliable for describing the boundaries of R-D, D-T, T-U, R\&D-T, T-U\&A, and R\&D-T\&U. These boundaries are illustrated in Figures 6 and 7. The quantitative boundaries are expressed as 2-D lines without the data points in Figure 8.

\section{Application to the 2011 Tohoku-Oki Tsunami Deposit}

We apply our results here for the reconstruction of the paleoflow velocity of the 2011 Tohoku-Oki tsunami deposit. Paleoflow velocities can be reconstructed by solving the discriminant functions for $U$. The discriminant functions which are in the dimensionless form $f_{\mathrm{ND}}\left(D_{*}, \tau_{*}, F r\right)=0$ or $f_{\mathrm{ND}}\left(D^{0}, U^{0}, h^{0}\right)=0$ can be recast in the dimensional form $f_{\mathrm{D}}\left(U, D_{50}, h\right)=0$. Consequently, the flow velocity $U$ is obtained by substituting $D_{50}$ and $h$ into the recast dimensional discriminant functions.

Table 3

Coefficients of Discriminant Functions Expressed in Terms of $\log _{10} D^{0}-\log _{10} U^{0}-\log _{10} h^{0}$ Axes

\begin{tabular}{lcccccccccc}
\hline Boundary & $\alpha_{1}$ & $\alpha_{2}$ & $\alpha_{3}$ & $\alpha_{4}$ & $\alpha_{5}$ & $\alpha_{6}$ & $\alpha_{7}$ & $\alpha_{8}$ & $\alpha_{9}$ \\
\hline L-R & 9.6579 & 48.535 & -6.1939 & -80.509 & 6.2728 & -6.5707 & 75.981 & -15.832 & 37.845 & -95.503 \\
R-D & 6.8182 & -8.8847 & 7.7118 & 2.2824 & 17.205 & 3.3619 & -24.329 & -19.281 & -74.929 & 133.65 \\
D-T & -1.0718 & -15.016 & -1.2217 & 0.41986 & -19.432 & -2.0878 & 0.20258 & 146.65 & 29.911 & -163.24 \\
T-U & 4.268 & 69.347 & 0.38717 & -17.728 & -0.80278 & 4.0865 & 5.9918 & -192.79 & -5.6765 & 154.38 \\
U-A & 1.4488 & -42.174 & -7.0204 & -3.4779 & 35.455 & 3.6859 & -9.2341 & 29.871 & -16.851 & 6.7306 \\
A-C & -14.965 & -9.8653 & -11.258 & -21.656 & 24.302 & 33.034 & -54.844 & -40.14 & 11.278 & 39.842 \\
D-U & 3.1962 & 54.331 & -0.83458 & -17.308 & -20.235 & 1.9987 & 6.1944 & -46.134 & 24.234 & -8.8574 \\
R\&D-T & 0.049927 & -32.149 & -0.74641 & -3.1144 & -16.902 & -1.8706 & 2.3732 & 192.4 & 22.602 & -185.24 \\
T-U\&A & 4.9597 & 66.845 & -0.14943 & -17.791 & 2.1128 & 5.1229 & 1.3442 & -192.1 & -8.4096 & 160.11 \\
R\&D-T\&U & 3.5783 & 32.145 & -0.38636 & -19.83 & -17.85 & 1.2205 & 11.329 & 14.627 & 18.463 & -46.464 \\
T\&U-A & 2.1884 & -37.122 & -6.9932 & -4.4898 & 35.6 & 4.6814 & -12.198 & 14.851 & -18.388 & 22.336 \\
\hline
\end{tabular}

Note. All abbreviations are as defined in Table 1. 
Table 4

Error Rates of Each Function

\begin{tabular}{lccccc}
\hline & \multicolumn{2}{c}{$\log _{10} D_{*}-\log _{10} \tau_{*}-\log _{10} F r$} & & \multicolumn{2}{c}{$\log _{10} D^{0}-\log _{10} U^{0}-\log _{10} h^{0}$} \\
\cline { 2 - 3 } \cline { 5 - 6 } Boundary & $E_{\mathrm{App}}(\%)$ & 15.188 & 27.339 & $E_{\mathrm{LOO}}(\%)$ \\
\hline L-R & 15.067 & 19.043 & & 18.908 & 27.582 \\
R-D & 18.863 & 14.562 & 10.259 & 18.998 \\
D-T & 14.396 & 35.151 & 33.204 & 10.370 \\
T-U & 34.567 & 33.095 & 35.593 & 34.177 \\
U-A & 32.917 & 6.7982 & 11.623 & 35.772 \\
A-C & 6.1404 & 17.687 & 21.115 & 11.842 \\
D-U & 17.550 & 13.021 & 8.5366 & 21.207 \\
R\&D-T & 12.785 & 24.741 & 22.668 & 8.5759 \\
T-U\&A & 24.326 & 22.448 & 20.506 & 22.806 \\
R\&D-T\&U & 22.418 & 32.619 & 36.006 & 20.598 \\
T\&U-A & 32.205 & & & &
\end{tabular}

Note. Here $E_{\mathrm{App}}$ is apparent error rate and $E_{\mathrm{LOO}}$ denotes results of leave-one-out cross validation.

When we apply the discriminant functions to the sedimentary structures in rock records, it is necessary to consider the process of bedform development and the preservation potential of bedforms, since bedforms are not always at their equilibrium state. However, the discriminant functions considering the nonequilibrium conditions are not currently available, so that we assume the equilibrium state and intact preservation of bedforms as an approximation for the estimation of paleoflow conditions. Bedform preservation under nonequilibrium conditions is a future challenge for the definition of bedform phase diagrams.

We analyzed the tsunami deposit at Rikuzentakata City reported by Naruse et al. (2012). The deposit at Locality 93 of Naruse et al. (2012) shows cross laminae of dunes overlain by parallel laminae of upper plane beds (see Naruse et al., 2012, Figure 6C). This succession of sedimentary structures implies that the bed state was transiting from dunes to upper plane beds. Here we estimate the paleoflow condition at the time when this bedform transition occurred. The discriminant function of these two bedform phases must be equal to 0 at this timing. In this study, the discriminant function between the dune region and the upper plane bed region is defined as follows:

$$
\begin{aligned}
& 3.8197\left(\log _{10} D_{*}\right)^{2}+19.559\left(\log _{10} \tau_{*}\right)^{2}-7.6881\left(\log _{10} F r\right)^{2} \\
& +0.8349 \log _{10} D_{*} \log _{10} \tau_{*}+19.866 \log _{10} \tau_{*} \log _{10} F r+13.288 \log _{10} D_{*} \log _{10} F r \\
& -12.537 \log _{10} D_{*}-0.49125 \log _{10} \tau_{*}+9.6489 \log _{10} F r+12.71=0
\end{aligned}
$$

We employ the relation of Keulegan (1938) to estimate $u_{*}$, since $S$ cannot be determined in this case. The shear velocity $u_{*}$ is defined as follows:

$$
u_{*}=\frac{U}{C_{z}}
$$

with

$$
C_{\mathrm{z}}=\frac{1}{\kappa} \log \left(\frac{11 h}{k_{\mathrm{s}}}\right)
$$

Here $C_{z}$ denotes the nondimensional Chézy coefficient according to Keulegan (1938), $\kappa$ is the Karman constant $(=0.4)$, and $k_{\mathrm{s}}$ is the roughness height. The roughness height $k_{\mathrm{s}}$ is estimated by $k_{\mathrm{s}}=2.5 D_{50}$. The reduced form of equation (13) with $D_{50}=0.3635 \times 10^{-3} \mathrm{~m}$ and $T=20^{\circ} \mathrm{C}$ is obtained as follows:

$$
\begin{aligned}
& 9.7477 \log \frac{U}{9.81 h^{\frac{1}{2}}}+0.13582 \log \frac{27.193 U^{2}}{(\log 12105 h)^{2}}+0.059509\left\{\log \frac{27.193 U^{2}}{(\log 12105 h)^{2}}\right\}^{2} \\
& +3.6891 \log \frac{U}{9.81 h^{\frac{1}{2}}} \log \frac{27.193 U^{2}}{(\log 12105 h)^{2}}-1.4501\left(\log \frac{U}{9.81 h^{\frac{1}{2}}}\right)^{2}+4.1793=0
\end{aligned}
$$



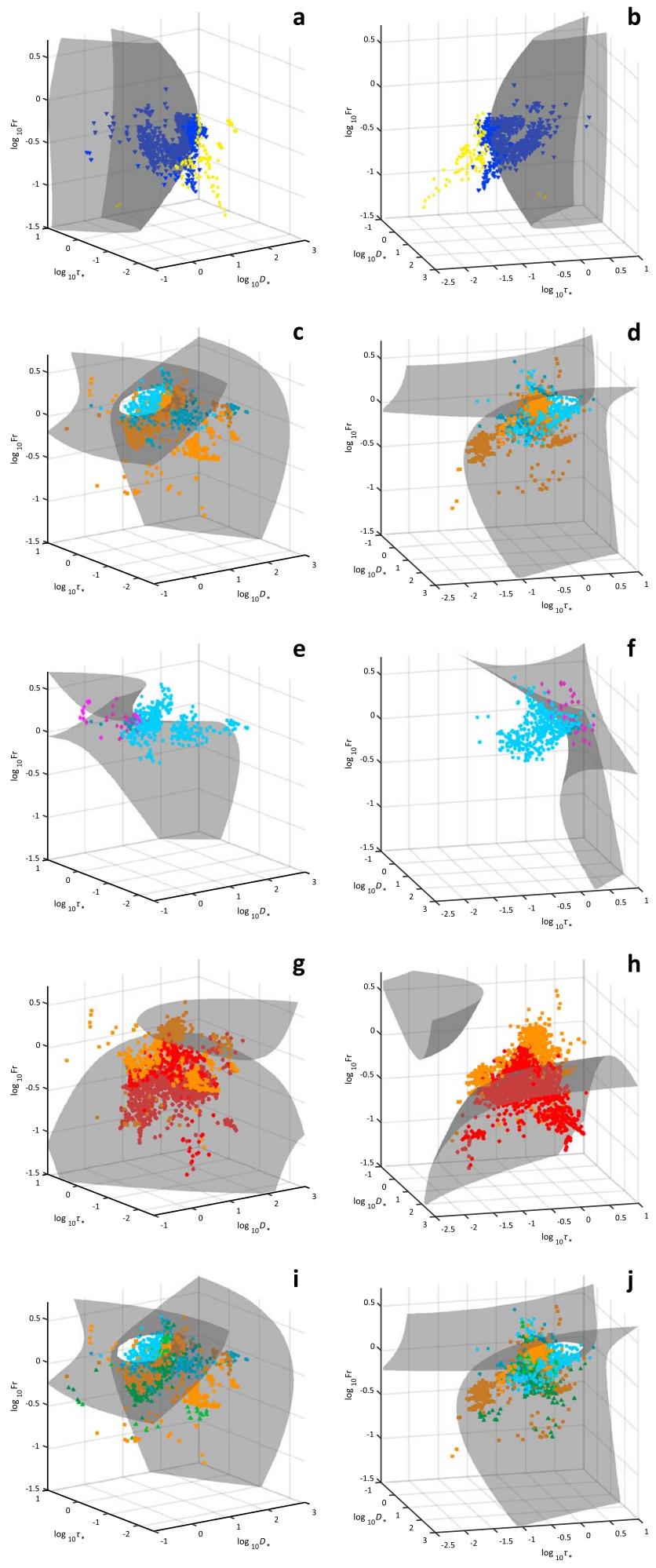

Lower-plane beds $\mathbf{\nabla}$ Ripples Dunes $\Delta$ Transition

II Upper-plane beds * Antidunes $\quad$ Cyclic steps

Figure 6. Discriminant functions expressed as quadratic surfaces in a $\log _{10} D_{*}-\log _{10} \tau_{*}-\log _{10} \operatorname{Fr} 3-\mathrm{D}$ diagram. The gray surfaces separate two fields of bedform type. Each of the surfaces is viewed from two different angles. $(a, b) L-R$ boundary; ( $c$, d) U-A boundary; (, f) A-C boundary; $(g, h)$ D-U boundary; and ( $i$, j) T\&U-A boundary. All abbreviations are as defined in Table 1. 

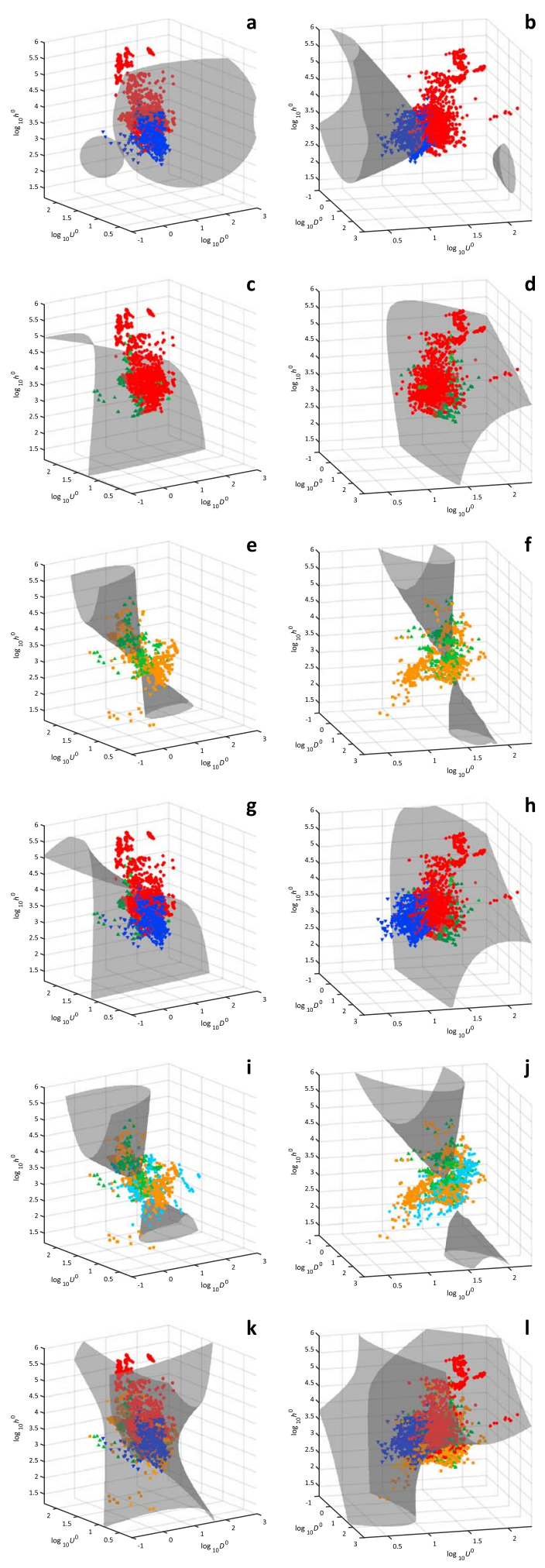

$\nabla$ Ripples $\bullet$ Dunes $\quad \Delta$ Transition
$\square$ Upper-plane beds $\#$ Antidunes

Figure 7. Discriminant functions expressed as quadratic surfaces in a $\log _{10} D^{0}-\log _{10} U^{0}-\log _{10} h^{0} 3-D$ diagram. The gray surfaces separate two bedform fields of bedform type. Each of the surfaces is viewed from two different angles. $(a, b)$ R-D boundary; (c, d) D-T boundary; (e, f) T-U boundary; $(g, h)$ R\&D-T boundary; (i, j) T-U\&A boundary; and ( $k$, l) R\&D-T\&U boundary. All abbreviations are as defined in Table 1. 

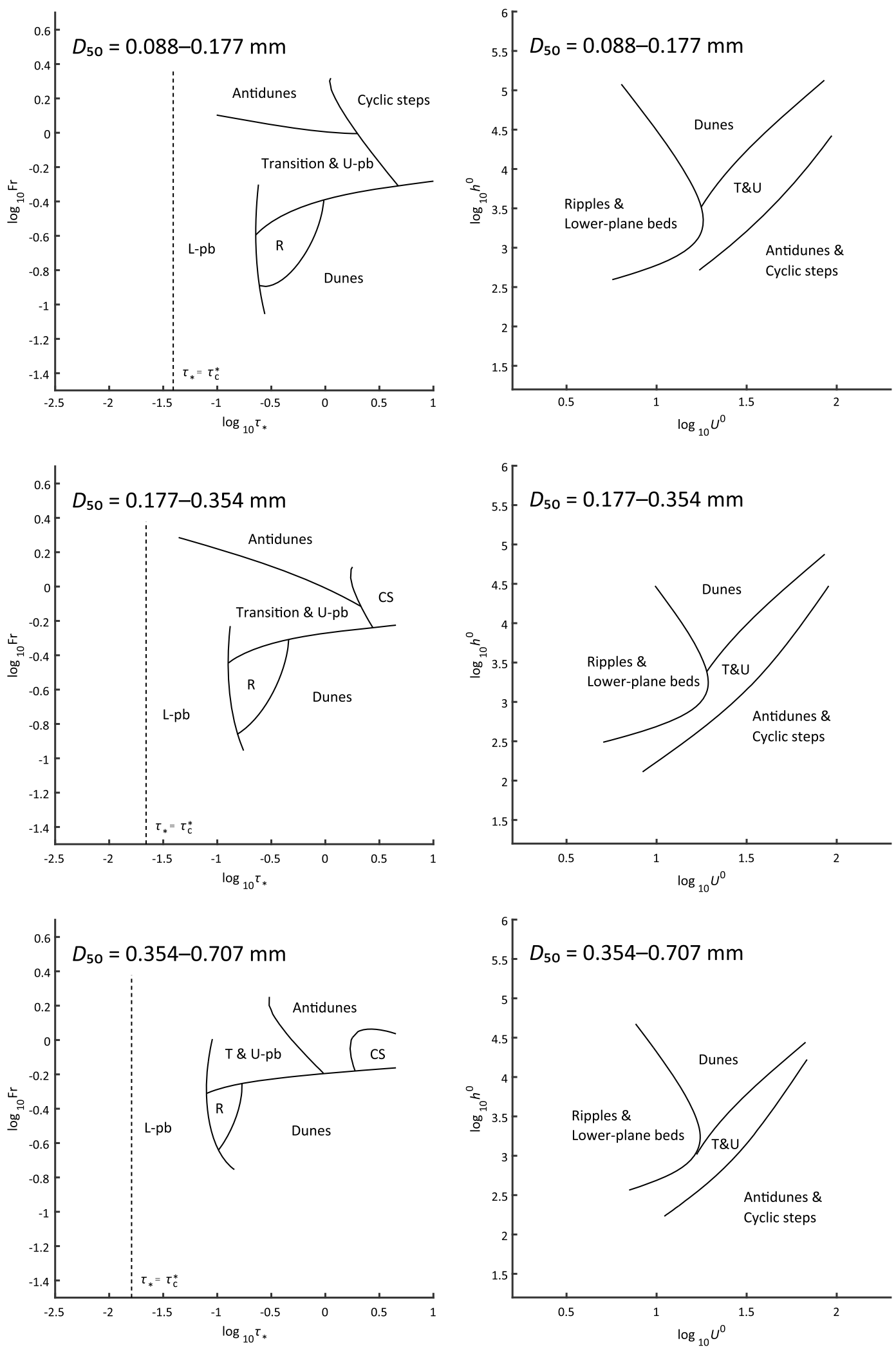

Figure 8. (left column) Schematic diagrams of $\log _{10} \tau_{*}-\log _{10} \mathrm{Fr}$ for fine, medium, and coarse sand. Dashed lines denote the critical Shields number defined by Garcia (2008) as follows: $\tau_{c}^{*}=\left[0.22 R e_{p}{ }^{-0.6}+0.06 \exp \left(\operatorname{Re}_{p}{ }^{-0.6}\right)\right] / 2$. (right column) Schematic diagrams of $\log _{10} U^{0}-\log _{10} h^{0}$ for fine, medium, and coarse sand. 
Table 5

Estimated Values of Paleoflow Velocity at the Transition From Dunes to Upper Plane Beds

\begin{tabular}{lc}
\hline Method & Paleoflow velocity $(\mathrm{m} / \mathrm{s})$ \\
\hline Naruse et al. (2012) & $3.0<$ \\
Fritz et al. $(2012)$ & $3.0-11.0$ \\
This study $(h=0.8 \mathrm{~m})$ & 0.449 or 1.905 \\
This study $(h=2 \mathrm{~m})$ & 0.416 or 3.239 \\
This study $(h=9 \mathrm{~m})$ & 0.382 or 7.271 \\
\hline
\end{tabular}

Although the representative grain size can be measured from the deposit, reconstruction of the paleoflow velocity by equation (16) requires estimates of the flow height $h$. Fritz et al. (2012) reported that the maximum tsunami height at Kesennuma Bay reached $9 \mathrm{~m}$ and the mean height after its peak was 1-2 m. Over time, tsunami height diminished to about $0.8 \mathrm{~m}$. The inundating flow height of the Tohoku-Oki Tsunami was nearly constant (1-2 m) for about $20 \mathrm{~min}$. It is known that bedforms can be established within 5 min on sandy beds Baas et al. (2013). For this reason, we conclude that data for equilibrium bedforms can be used as an approximation in this case. We set the values of $0.8,2$, and $9 \mathrm{~m}$ as possible values for the flow height at the study site.

As a result of the solution of equation (16), we obtained estimates of the velocity of the backwash flow ranging from 0.382 to $0.449 \mathrm{~m} / \mathrm{s}$ and 1.90 to $7.27 \mathrm{~m} / \mathrm{s}$ (Table 5). Figure 9 shows bedform phases of dunes and upper plane beds projected on the $\log _{10} \tau_{*}-\log _{10} \mathrm{Fr}$ plane and the result of reconstruction. The value of $\log _{10} D_{*}$ plotted in this diagram ranges from 0.863 to 1.063 (7.29 $\leq$ $D_{*} \leq 11.6$ ). The dashed line denotes equation (13) with $D_{50}=0.3635 \times 10^{-3} \mathrm{~m}$ and $T=20^{\circ} \mathrm{C}$.

It should be noted that the discriminant functions can have multiple real number solutions because they are quadratic polynomial functions. In other words, as a result of solutions of the discriminant functions, we may obtain multiple values of the flow velocities corresponding to a single value of flow depth. These multiple solutions require careful examination for judging whether or not the results are applicable. In the case of this study, small estimates of flow velocities $(0.382,0.416$, and $0.449 \mathrm{~m} / \mathrm{s})$ and large estimates $(1.905,3.239$, and $7.271 \mathrm{~m} / \mathrm{s}$ ) were obtained as solutions of the discriminant functions. All the small estimates and the large estimate for a flow depth of $0.8 \mathrm{~m}(1.905 \mathrm{~m} / \mathrm{s})$ are lower than the threshold velocity of critical motion of the largest grains in the deposit $(3.0 \mathrm{~m} / \mathrm{s})$ reported by Naruse et al. (2012). As a result, they were not considered as reasonable solutions. Accordingly, the large flow velocities for flow depths of 2 and $9 \mathrm{~m}$ ( 3.239 and $7.271 \mathrm{~m} / \mathrm{s}$ ) were interpreted as probable values of the tsunami backwash flow velocity (Figure 10). These probable values are consistent with the estimates of previous studies. Fritz et al. (2012) determined the velocity of the tsunami surface current at Kesennuma Bay using digital particle image velocimetry analysis. They estimated that the flow velocity ranged from 3 to $11 \mathrm{~m} / \mathrm{s}$ at flow depth of about $2-3 \mathrm{~m}$. Their measurements imply that

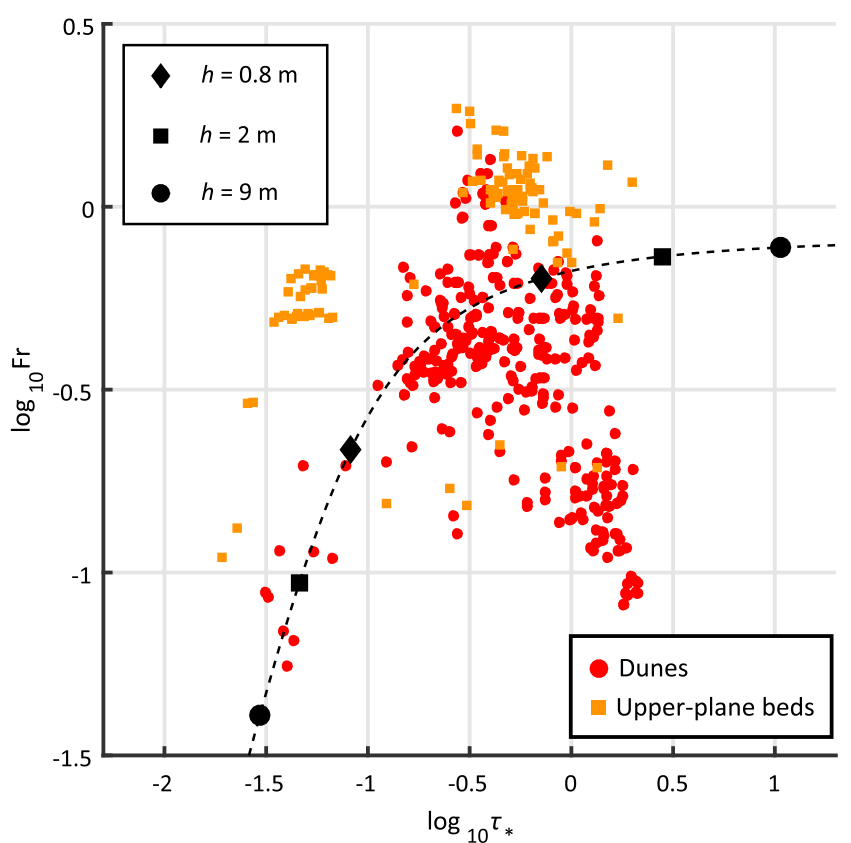

Figure 9. The values of $\log _{10} \tau_{*}$ and $\log _{10} F r$ for given values of flow depth. Black rhombuses, squares, and circles denote the results at flow depths $h$ of $0.8,2$, and $9 \mathrm{~m}$, respectively. The dashed line is equation (13) with $D_{50}=0.3635 \times 10^{-3} \mathrm{~m}$ and $T=20^{\circ} \mathrm{C}$. The discriminant function which includes the reconstructed data is only described in this figure. our discriminant functions are useful to reconstruct paleoflow velocities from geologic records.

\section{Discussion}

5.1. Significance of the Dimensionless 3-D Bedform Phase Diagrams The bedform phase diagrams presented here, which employ dimensionless governing parameters, are useful for a variety of purposes. Southard and Boguchwal (1990) produced a series of 2-D diagrams using governing parameters that are not in dimensionless form. Although the use of dimensional parameters is useful to understand the characteristics of bedform phase intuitively, dimensional phase diagrams are difficult to apply to large-scale flows because of relative paucity of large-scale experimental data. In contrast, dimensionless diagrams can be applied to large-scale flows including not only river flows but also subaqueous gravity currents or flows on other planets (Baas et al., 2000; Kleinhans, 2005a; van den Berg \& van Gelder, 1993). For instance, Kleinhans (2005a) produced a diagram that shows the boundaries of bedform phases on Earth and Mars. The acceleration of gravity is included in the dimensionless parameters, so that the diagrams are valid even in planets with gravitational accelerations or flowing fluids that differ from Earth.

Our diagrams incorporate data for both Fr-subcritical and Fr-supercritical flow regimes. The bedforms for both Fr-subcritical and supercritical flow regimes have rarely been described together in previous dimensionless 2-D bedform diagrams, such as the diagram by van den Berg and van Gelder (1993). The diagram of Cartigny et al. (2014) used the Froude 


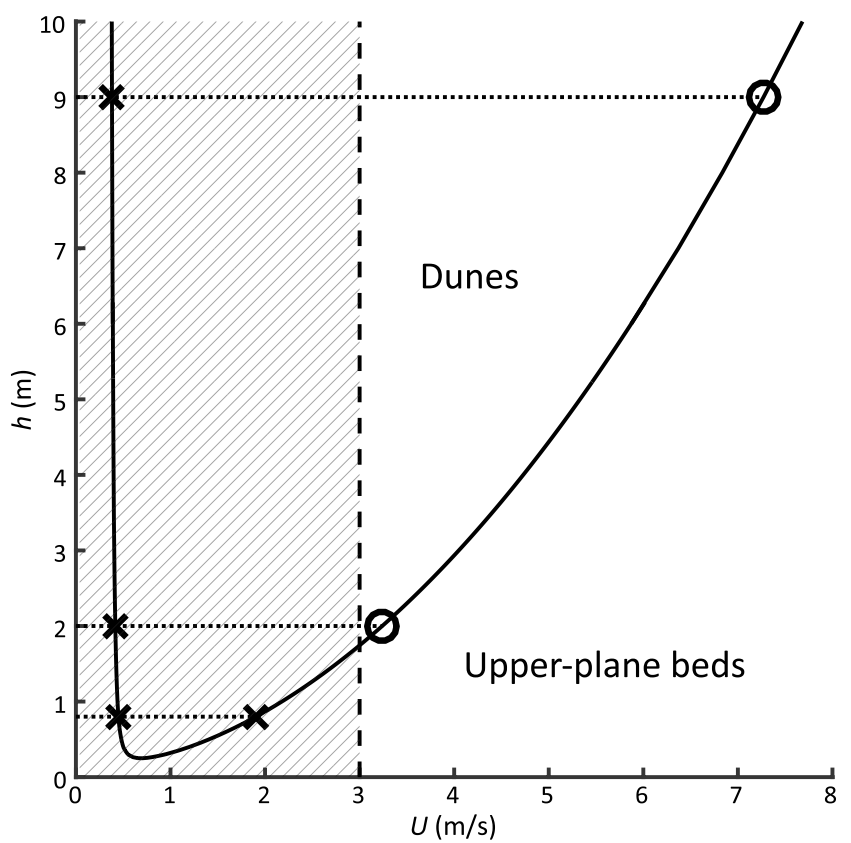

Figure 10. Estimation of tsunami paleoflow velocity. The solid line is equation (16), and oblique pattern denotes the region for $U$ below the threshold velocity of critical motion of the largest grains in the deposit $(3.0 \mathrm{~m} / \mathrm{s})$ reported by Naruse et al. (2012). The circles denote the solutions which exceed $3.0 \mathrm{~m} / \mathrm{s}$, and the crosses denote the solutions which are lower than $3.0 \mathrm{~m} / \mathrm{s}$. number as an axis to illustrate the transition from upper plane bed regimes to Fr-supercritical flow regime, but it does not focus on Fr-subcritical bedforms.

As a result of the incorporation of $\mathrm{Fr}$ as an axis in addition to flow velocity and sediment diameter parameters, our diagrams inevitably became 3-D diagrams. The 3-D diagrams clearly show the spatial extent of bedform phase regimes, whereas there appears to be many overlapping regions of bedform phase in 2-D diagrams such as that of van den Berg and van Gelder (1993). This same behavior is apparent when our 3-D phase diagrams are projected into 2-D, as shown in Figures 3 and 5. In Figure 3a, for instance, the domain corresponding to $-0.5<\log _{10} \tau_{*}<0$ and $0.5<\log _{10} D_{*}<1\left(0.316<\tau_{*}<1\right.$ and $\left.3.16<D_{*}<10\right)$ contains data for several kinds of bedforms. This demonstrates that overlapping regions in 2-D diagrams occur as the result of projection of 3-D diagrams. Stability conditions for bedforms are thus better defined in three-dimensional parametric space.

\subsection{Comparison With Previous Discriminant Functions for Bedform Phase}

The discriminant functions based on the new 3-D diagrams express quantitatively the boundaries between bedform regimes. Although a few studies have proposed discriminant functions, our method is superior in terms of reproducibility and ease of application to natural flows. Our discriminant functions can be easily updated when new laboratory or field data become available, because our method can be used irrespective of the number of data points.

Here we compare our functions with those of previous studies, in which the boundaries of bedform regime were expressed using the value of Fr (Karim, 1995; Kennedy, 1963). Figure 11 shows a diagram using the logarithmic form of $h / D_{50}$ and $F r$ for its axes, as per the diagram of Karim (1995). Our data set is plotted with three lines showing boundaries of previous studies. The dashed line is $\log _{10} F r=-0.0737(F r=0.844)$, which denotes the discriminator derived theoretically by (Kennedy, 1963), and the two solid lines denote criteria proposed by Karim (1995). The diagram shows that lower plane beds occur for $\log _{10} F r$ less than 0. Data points for ripples and dunes are scattered around the field for $\log _{10} F r$ less than 0.2 and for $\log _{10} h / D_{50}$ between 1 and about 5 ( $F r<1.58$ and $\left.10 \leq h / D_{50} \leq 10^{5}\right)$. The transition region overlaps other regions, including dune and upper plane bed regions. Most transition data points fall in the region corresponding to $\log _{10} F r$ larger than -0.4 and $\log _{10} h / D_{50}$ lower than $4\left(0.398<F r\right.$ and $\left.h / D_{50}<10^{4}\right)$. Upper plane beds are positioned in the range for which $\log _{10} F r$ is larger than -0.4 and for which $\log _{10} h / D_{50}$ falls between 1 and $5(0.398<F r$ and $10 \leq h / D_{50} \leq 10^{5}$ ). Antidunes and cyclic steps are formed above a value of $\log _{10} \operatorname{Fr}$ of -0.2 and below a value of $\log _{10} h / D_{50}$ of $3.5\left(0.631<F r\right.$ and $\left.h / D_{50}<3162\right)$.

Kennedy (1963) and Karim (1995) published equations using Fr to express the threshold conditions of bedform phase. Kennedy (1963) stated that the bedform phase transition from upper plane beds to antidunes occurs when the Froude number equals 0.844 . The apparent error rate of the criterion $\mathrm{Fr}=0.844$ is found to be $32.3 \%$ (Figure 11) from our data set, while the apparent error rate of our discriminant function in the $\log _{10} D_{*}-\log _{10} \tau_{*}-\log _{10} \mathrm{Fr}$ diagram is $32.9 \%$. The apparent error rates of our functions and $\mathrm{Fr}=0.844$ are nearly equal; however, many points of upper plane beds plot above the criterion $\mathrm{Fr}=0.844$ as shown on Figure 11 . In fact, $46.6 \%$ of upper plane beds plot above $\mathrm{Fr}=0.844$, whereas $8.4 \%$ of antidunes plot below the criterion. Thus, Kennedy's criterion generally fails to predict the upper plane beds even though the total apparent error rate seems identical to our study. On the other hand, the apparent error rates of our discriminant function for upper plane beds and antidunes are $35 \%$ and $29.5 \%$, respectively. Hence, our discriminant function represents an improvement of the previous criterion $\mathrm{Fr}=0.844$ to predict the boundary between upper plane beds and antidunes. 


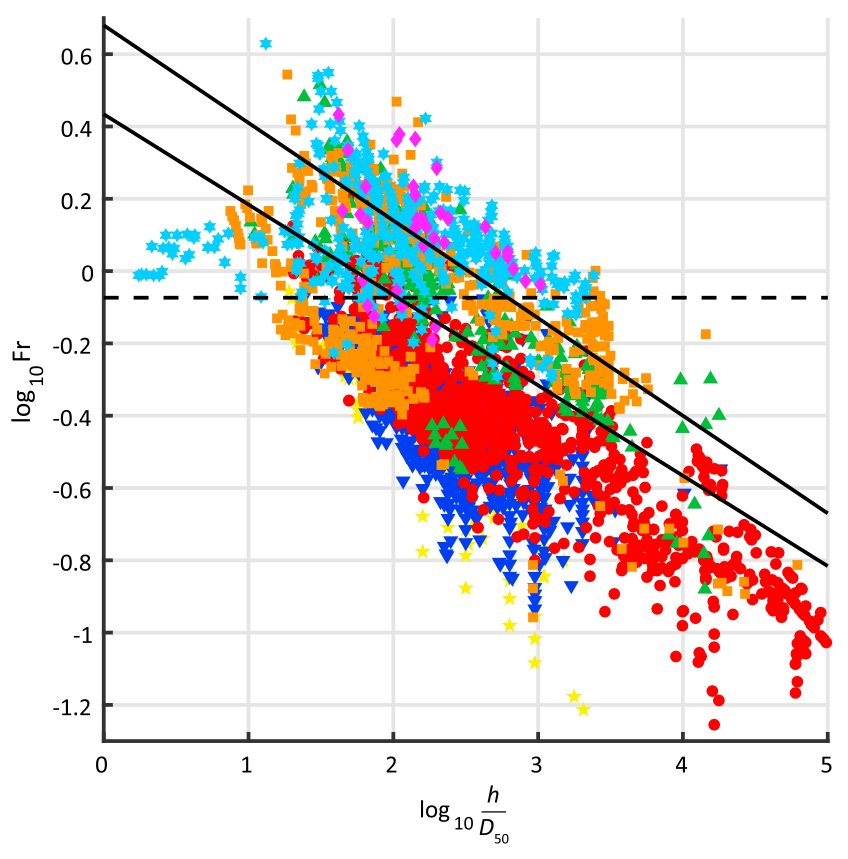

Lower-plane beds $\nabla$ Ripples Dunes $\Delta$ Transition

Upper-plane beds * Antidunes Cyclic steps

Figure 11. Diagram of $\log _{10} \frac{h}{D_{50}}-\log _{10} F r$ with the criteria $F r=0.844$, equations (17) and (18). The dashed line denotes $\log _{10} F r=-0.0737$ $(F r-=0.844)$. The lower and upper solid lines correspond to equations (17) and (18), respectively.
Karim (1995) proposed two discriminant functions $F_{t}$ and $F_{u}$ for boundaries between (i) the lower flow and transition regimes and (ii) the transition and upper flow regimes. These take the following respective forms

$$
\begin{aligned}
& F_{t}=2.716\left(\frac{h}{D_{50}}\right)^{-0.25} \\
& F_{u}=4.785\left(\frac{h}{D_{50}}\right)^{-0.27}
\end{aligned}
$$

The apparent error rates of these functions are $8.77 \%$ and $53.3 \%$, respectively. The apparent error rates of the function $F_{t}$ and $F_{u}$ were higher than those of this study (8.54\% and $22.7 \%)$. Although the apparent error rate of $F_{t}$ was low since the boundary between the lower flow and transition regimes happens to be linear in the $\log _{10} \frac{h}{D_{50}}-\log _{10} F r$ plane, other boundaries of bedform phase generally show curved geometry. Our method is suitable to obtain the discriminant functions for any combinations of bedform phase.

In addition, the reliability of the boundaries published by previous studies cannot be tested with statistical methods such as the information criterion since it was derived by theoretical analysis. This study corresponds to first comprehensive attempt to perform the statistical analysis of bedform formative conditions, and we infer that comparison of functions using the information criterion will be effective when other discriminant functions are proposed in future studies.

\subsection{Evaluation of Boundary Properties Between Bedform Phase Using Discriminant Analysis}

Discriminant analysis enables us to evaluate the characteristics of the boundaries of bedform phase in terms of analytical error rates. In the phase diagram of Southard and Boguchwal (1990), modes of bed phase transitions were evaluated qualitatively, using terms such as "abrupt" or "gradual" (see Southard \& Boguchwal, 1990, Figure 8). This study provides a quantitative evaluation for the mode of bedform phase transition using the error rates of discriminant functions. Higher error rates of discriminant functions imply that the corresponding boundaries are rather diffuse or different regions of bedform phase overlap. Lower error rates of the discriminant functions indicate that the boundaries between bedform phases are well defined in the parametric space, suggesting that the bedform phase transition is abrupt.

As a result of our discriminant analysis, we found that the apparent error rates are high (23-36\%) at the boundaries from the transition regime to upper regime bedforms ( $T-U, U-A$, and T-U\&A), while they are low $(<19 \%)$ at the boundaries from lower regime to the transition regime (R-D, D-T, and R\&D-T). The reason why the boundaries of the upper regime bedforms may not be clearly defined might be explained by invoking the theoretical analysis of Izumi and Parker (2009). Using a weakly nonlinear stability analysis, they predicted that the threshold conditions for the transition from plane bed to antidunes can be different from that for the transition from antidunes to plane bed. This hysteresis in bedform transition can be the reason for the overlapping region in the experimental data, because available research does not generally pertain to the change of flow conditions. Another possible explanation for the gradual transition of bedform phase is that the phase is actually a continuum, so that it can change its boundaries with slight perturbations of the conditions. Unclear boundaries or overlapping of bedform phases could also suggest that significant parameters have not been considered. This would suggest a need for further theoretical studies. Our method derives the empirical functions without any theoretical assumptions and therefore can provide an independent method for testing the validation of future theoretical analysis.

\subsection{Significance of Discriminant Analysis in Future Studies of Bedforms}

We infer that discriminant analysis of bedform phase will become more significant in future studies of bedforms. Recent studies have suggested additional governing parameters related to bedform formation. This means that bedform phase regimes may be defined in more than three dimensions, which is impossible to 
represent graphically. For example, the submerged specific gravity of sediment $R$ has been shown to be an important parameter for bedform formation (Yokokawa, Tsuji, et al., 2011). The density difference between sediment and water was not specifically included as an independent parameter in either previous diagrams or the present study, because it is nearly constant for siliciclastic particles in clear water. However, it can vary in case of pyroclastic flows and high concentration turbidity currents, as well as for flume experiments using plastic particles. Further, Baas et al. (2016) stated that it is important to understand the effect of cohesive material content on the formation of bedforms. Baas et al. (2016) used the fraction of cohesive material in the sediment as a new parameter in their diagram. Moreover, if bedform phase diagrams are extended to bedforms of waves and combined flows, the number of axes will increase more and more. The results of these studies suggest the addition of extra axes to our 3-D diagram of bedform phase, again making it impossible to visualize. This notwithstanding, our method can still yield discriminant functions irrespective of the number of parametric axes, as well as the number of data points and bedform types. We can derive formative conditions using discriminant analysis, and the properties of bed phase boundaries can be examined from the error rates of the analysis without any visualization. Thus, as the study of bedforms advances in future, our methodology has the potential to provide further useful information about bedforms.

\section{Conclusions}

We compiled 3,793 open-channel flow laboratory and field data from previous studies. On the basis of this data set, new bedform phase diagrams, which express the formative fields of bedforms, were developed. We then derived discriminant functions using discriminant analysis with the concept of the Mahalanobis distance. The new bedform phase diagrams and discriminant functions enable us to analyze sedimentary structures without arbitrary assumptions. As an example, we calculated the paleoflow velocity of tsunami. We show that our method provides reasonable estimates of the velocity of the flow. Our method is also pertinent for the quantitative examination of the characteristics of bed phase transitions.

\section{Appendix A: Side Wall Correction}

The side wall corrected Shields mobility number $\tau_{\mathrm{b}}^{*}$ is calculated using the following procedures.

First, the dimensionless friction coefficient for the entire cross section is computed from the laboratory data with the Darcy-Weisbach resistance relation. Let $C_{\mathrm{f}}$ be the nondimensional friction coefficient, equal to $1 / C_{z}^{2}$. The dimensionless friction coefficient $C_{\mathrm{f}}$ is defined as

$$
C_{f}=\frac{S g r}{U^{2}}
$$

Here $r$ is the hydraulic radius for the entire cross section. In this method, the ratio between the dimensionless friction coefficient $C_{\mathrm{f}}$ and the Reynolds number $R e$ for the entire cross section must be computed. $R e$ is defined as

$$
R e=\frac{r U}{v}
$$

Recalling that $C_{f}=f / 8$, with $f$ denoting the Darcy-Weisbach friction factor, the ratio between the DarcyWeisbach friction coefficient and the Reynolds number is obtained as follows:

$$
\frac{f}{R e}=\frac{8 C_{f}}{R e}
$$

Second, the friction factor for the wall region $f_{\mathrm{w}}$ is estimated using the following equation (Chiew \& Parker, 1994):

$$
\frac{1}{\sqrt{f_{\mathrm{w}}}}=-0.86 \log \left(\frac{\epsilon_{\mathrm{w}} / 4 r_{\mathrm{w}}}{3.7}+\frac{2.51}{\operatorname{Re}_{\mathrm{w}} \sqrt{f_{\mathrm{w}}}}\right)
$$

where $\epsilon_{\mathrm{w}}$ denotes wall roughness, $r_{\mathrm{w}}$ denotes hydraulic radius for the wall region, and $R e_{\mathrm{w}}$ denotes Reynolds number for the wall region. We assumed that flume sidewalls are smooth, so that $\epsilon_{\mathrm{w}}$ equals 0 . Equation (A4) 
must be solved iteratively because the friction factor is on both sides of the equation. The first estimate of $f_{w^{\prime}}$ $f_{\mathrm{w}, 0}$, is executed using the Blasius equation as follows:

$$
f_{\mathrm{w}, 0}=0.398\left(\frac{f}{R e}\right)^{\frac{1}{5}}
$$

The assumption that the friction slope for the entire cross section is equal to the friction slope in the bed and in the wall region implies that the ratio between the Reynolds number and the friction factor is constant. Thus, the Reynolds number for the wall region is computed as follows:

$$
R e_{\mathrm{w}}=f_{\mathrm{w}, 0}\left(\frac{f}{R e}\right)^{-1}
$$

The estimates, $f_{\mathrm{w}, \mathrm{i}}$ and $R e_{\mathrm{w}, \mathrm{i}}$, are calculated as functions of the values obtained one iteration prior, $f_{\mathrm{w}, \mathrm{i}-1}$ and $R e_{\mathrm{w}, \mathrm{i}-1}$. We repeat this procedure until the difference between $f_{\mathrm{w}, \mathrm{i}}$ and $f_{\mathrm{w}, \mathrm{i}-1}$ becomes sufficiently small.

Third, the dimensionless friction coefficient for the wall region is computed by

$$
C_{\mathrm{fw}}=\frac{f_{\mathrm{w}}}{8}
$$

Next, from the conservation equation of streamwise momentum, the friction coefficient for the bed region $C_{\mathrm{fb}}$ is computed as

where $B$ is flume width.

$$
C_{\mathrm{fb}}=\frac{C_{\mathrm{f}}(B+2 h)-2 C_{\mathrm{fw}} h}{B}
$$

Finally, the side wall corrected Shields mobility number $\tau_{\mathrm{b}}^{*}$ is given by

$$
\tau_{\mathrm{b}}^{*}=\frac{C_{\mathrm{fb}} U^{2}}{R g D_{50}}
$$

Acknowledgments

This work was partially supported by JSPS Grant-in-Aid for Scientific Research(B) grant JP26287127 and JSPS Grant-in-Aid for Scientific Research(B) grant JP15H03739. The data used for the analysis is uploaded as supporting information Unpublished data used for the analysis are cited from the data set of Brownlie (1981). We would like to express our gratitude to Gary Parker for his comments and encouragement. We are also thankful to the Editor, Giovanni Coco, the Associate Editor, and the three reviewers, Sean Bennett, Ray Kostaschuk, and an anonymous reviewer for their insightful comments and suggestions.

\section{References}

Alexander, J., Bridge, J. S., Cheel, R. J., \& Leclair, S. F. (2001). Bedforms and associated sedimentary structures formed under supercritical water flows over aggrading sand beds. Sedimentology, 48(1), 133-152. https://doi.org/10.1046/j.1365-3091.2001.00357.x

Alho, P., Baker, V. R., \& Smith, L. N. (2010). Paleohydraulic reconstruction of the largest glacial lake Missoula draining(s). Quaternary Science Reviews, 29(23-24), 3067-3078. https://doi.org/10.1016/j.quascirev.2010.07.015

Allen, J. R. L. (1982). Sedimentary structures: Their character and physical basis (Vol. 1). Amsterdam: Elsevier Scientific Publishing Company. Ashley, G. M. (1990). Classification of large-scale subaqueous bedforms: A new look at an old problem - SEPM bedforms and bedding structures. Journal of Sedimentary Petrology, 60(1), 160-172.

Baas, J. H., Best, J. L., \& Peakall, J. (2016). Predicting bedforms and primary current stratification in cohesive mixtures of mud and sand. Journal of the Geological Society, 173(1), 12-45. https://doi.org/10.1144/jgs2015-024

Baas, J. H., Best, J. L., Peakall, J., \& Wang, M. (2009). A phase diagram for turbulent, transitional, and laminar clay suspension flows. Journal of Sedimentary Research, 79(4), 162-183. https://doi.org/10.2110/jsr.2009.025

Baas, J. H., Davies, A. G., \& Malarkey, J. (2013). Bedform development in mixed sand-mud: The contrasting role of cohesive forces in flow and bed. Geomorphology, 182, 19-32. https://doi.org/10.1016/j.geomorph.2012.10.025

Baas, J. H., van Dam, R., \& Storms, J. (2000). Duration of deposition from decelerating high-density turbidity currents. Sedimentary Geology, 136(1-2), 71-88. https://doi.org/10.1016/S0037-0738(00)00088-9

Best, J. L. (2005). The fluid dynamics of river dunes: A review and some future research directions. Journal of Geophysical Research, 110, F04S02. https://doi.org/10.1029/2004JF000218

Best, J. L., Kostaschuk, R. A., \& Villard, P. V. (2001). Quantitative visualization of flow fields associated with alluvial sand dunes: Results from the laboratory and field using ultrasonic and acoustic Doppler anemometry. Journal of Visualization, 4(4), $373-381$. https://doi.org/10.1007/BF03183900

Bonnefille, R. (1963). Essais de synthèse des lois de début d'entraînement des sédiments sous l'action d'un courant en régime continu. Bulletin du Centre de Recherches et d'Essais de Chatou, 5, 67-72.

Bridge, J. S., \& Best, J. L. (1988). Flow, sediment transport and bedform dynamics over the transition from dunes to upper-stage plane beds: Implications for the formation of planar laminae. Sedimentology, 35(5), 753-763. https://doi.org/10.1111/j.1365-3091.1988.tb01249.x

Bridge, J. S., \& Demicco, R. (2008). Earth Surface Processes, Landforms and Sediment Deposits. Cambridge: Cambridge University Press. Brownlie, W. R. (1981). Compilation of fluvial channel data: Laboratory and field (Report KH-R43B). Pasadena, CA: W. M. Keck Laboratory of Hydraulics and Water Resources, California Institute of Technology.

Cartigny, M. J., Ventra, D., Postma, G., \& van den Berg, J. H. (2014). Morphodynamics and sedimentary structures of bedforms under supercritical-flow conditions: New insights from flume experiments. Sedimentology, 61(3), 712-748. https://doi.org/10.1111/sed.12076

Chaubert, J., \& Chauvin, J. L. (1963). Formation des dunes et des rides dans les modèles fluviaux. Bulletin du Centre de Recherches et d'Essais de Chatou, 4, 31-51. 
Chiew, Y. M., \& Parker, G. (1994). Incipient sediment motion on non-horizontal slopes. Journal of Hydraulic Research, 32(5), 649-660. https://doi.org/10.1080/00221689409498706

de Maesschalck, R., Jouan-Rimbaud, D., \& Massart, D. (2000). The Mahalanobis Distance, Chemometrics and Intelligent Laboratory Systems, 50(1), 1-18. https://doi.org/10.1016/S0169-7439(99)00047-7

Dumas, S., Arnott, R., \& Southard, J. B. (2005). Experiments on oscillatory-flow and combined-flow bed forms: Implications for interpreting parts of the shallow-marine sedimentary record. Journal of Sedimentary Research, 75(3), 501-513. https://doi.org/10.2110/jsr.2005.039

Efron, B. (1986). How biased is the apparent error rate of a prediction rule? Journal of the American Statistical Association, 81(394), 461-470. https://doi.org/10.1080/01621459.1986.10478291

Fisher, R. A. (1936). The use of multiple measurements in taxonomic problems. Annals of Eugenics, 7(2), 179-188. https://doi.org/10.1111/j.1469-1809.1936.tb02137.x

Fritz, H. M., Phillips, D. A., Okayasu, A., Shimozono, T., Liu, H., Mohammed, F., ... Takahashi, T. (2012). The 2011 Japan tsunami current velocity measurements from survivor videos at Kesennuma Bay using lidar. Geophysical Research Letters, 39, L00G23. https://doi.org/10.1029/2011GL050686

Fujiwara, O., \& Tanigawa, K. (2014). Bedforms record the flow conditions of the 2011 Tohoku-Oki tsunami on the Sendai Plain, northeast Japan. Marine Geology, 358, 79-88. https://doi.org/10.1016/j.margeo.2014.04.013

Fukuoka, S., Okutsu, K., \& Yamasaka, M. (1982). Dynamic and kinematic features of sand waves in upper regime [in Japanese]. Proceedings of the Japan Society of Civil Engineers, 323, 77-89. Japan Society of Civil Engineers. https://doi.org/10.2208/jscej1969.1982.323_77

Garcia, M. H. (2008). Sediment transport and morphodynamics. In M. H. Garcia (Ed.), Sedimentation Engineering: Process, Measurements, Modeling and practice (Vol. 110, pp. 21-163). Reston, VA: ASCE manuals and reports on engineering practice. https://doi.org/10.1061/9780784408148.ch02

Guy, H. P., Simons, D. B., \& Richardson, E. V. (1966). Summary of alluvial channel data from flume experiments, 1956-61 (Report 462-I). Washington, DC: Professional Paper.

Hastie, T., Tibshirani, R., \& Friedman, J. (2009). The elements of statistical learning (2nd edn.). New York: Springer.

Hughes Clarke, J. E. (2016). First wide-angle view of channelized turbidity currents links migrating cyclic steps to flow characteristics. Nature Communications, 7(11896). https://doi.org/10.1038/ncomms 11896

Izumi, N., \& Parker, G. (2009). The bifurcation pattern of the flat bed and antidune transition [in Japanese]. Proceedings of Hydraulic Engineering, 53, 733-738. Japan Society of Civil Engineers.

Karim, F. (1995). Bed configuration and hydraulic resistance in alluvial-channel flows. Journal of Hydraulic Engineering, 121, 15-25. https://doi.org/10.1061/(ASCE)0733-9429(1995)121:1(15)

Kennedy, J. F. (1963). The mechanics of dunes and antidunes in erodible-bed channels. Journal of Fluid Mechanics, 16(4), 521-544. https://doi.org/10.1017/S0022112063000975

Keulegan, G. H. (1938). Laws of turbulent flow in open channels. Journal National Bureau of Standards, Research Paper, 1151(21), 707-741.

Kleinhans, M. G. (2005a). Flow discharge and sediment transport models for estimating a minimum timescale of hydrological activity and channel and delta formation on Mars. Journal of Geophysical Research: Planets, 110, E12003. https://doi.org/10.1029/2005JE002521

Kleinhans, M. G. (2005b). Phase diagrams of bed states in steady, unsteady, oscillatory and mixed flows. In L. C. Van Rijn et al. (Eds.), Sandpit project (pp. Q1-Q16). Amsterdam: Aqua Publications.

Kohavi, R. (1995). A study of cross-validation and bootstrap for accuracy estimation and model selection, Proceedings of the 14th International Joint Conference on Artificial Intelligence (Vol. 2, pp. 1137-1143). San Francisco, CA: Morgan Kaufmann Publishers Inc.

Mardia, K. V. (1970). Measures of multivariate skewness and kurtosis with applications. Biometrika, 57(3), 519-530. https://doi.org/10.1093/biomet/57.3.519

Mitchell, A. J., Ulicný, D., Hampson, G. J., Allison, P. A., Gorman, G. J., Piggott, M. D., Wells, M. R., \& Pain, C. C. (2010). Modelling tidal current-induced bed shear stress and palaeocirculation in an epicontinental seaway: The Bohemian Cretaceous Basin, Central Europe. Sedimentology, 57(2), 359-388. https://doi.org/10.1111/j.1365-3091.2009.01082.x

Naruse, H., Arai, K., Matsumoto, D., Takahashi, H., Yamashita, S., Tanaka, G., \& Murayama, M. (2012). Sedimentary features observed in the tsunami deposits at Rikuzentakata City. Sedimentary Geology, 282, 199-215. https://doi.org/10.1016/j.sedgeo.2012.08.012

Parker, G., \& Izumi, N. (2000). Purely erosional cyclic and solitary steps created by flow over a cohesive bed. Journal of Fluid Mechanics, 419, 203-238. https://doi.org/10.1017/S0022112000001403

Perillo, M. M., Best, J. L., \& Garcia, M. H. (2014). A new phase diagram for combined-flow bedforms. Journal of Sedimentary Research, 84(4), $301-313$. https://doi.org/10.2110/jsr.2014.25

Simons, D. B., \& Richardson, E. V. (1966). Resistance to flow in alluvial channels, U.S. Geological Survey Professional Paper 422-J.Washington, DC: U.S. Government Printing Office.

Simons, D. B., Richardson, E. V., \& Nordin, C. F. (1965). Sedimentary structures generated by flow in alluvial channels. In G. V. Middleton (Ed.), Primary Sedimentary Structures and Their Hydrodynamic Interpretation (Vol. 12, pp. 34-52). Fort Collins, CO: Society of Economic Paleontologists and Mineralogists Special Publication, SEPM.

Southard, J. B. (1991). Experimental determination of bed-form stability. Annual Review of Earth and Planetary Sciences, 19, 423-455. https://doi.org/10.1146/annurev.ea.19.050191.002231

Southard, J. B., \& Boguchwal, L. A. (1990). Bed configurations in steady unidirectional water flows. Part 2. Synthesis of flume data. Journal of Sedimentary Petrology, 60(5), 658-679.

van den Berg, J. H., \& van Gelder, A. (1993). A new bedform stability diagram, with emphasis on the transition of ripples to plane bed in flows over fine sand and silt. In M. Marzo, \& C. Puigdefabregas (Eds.), Alluvial sedimentation (Vol. 17, pp. 11-21). Boston, MA: Blackwell Scientific Publications, Special Publications, International Association of Sedimentologists.

Vanoni, V. A. (1974). Factors determining bed forms of alluvial streams. Journal of the Hydraulics Division, 100(3), 363-377.

Venditti, J. G. (2013). Bedforms in sand-bedded rivers. In J. Shroder, \& E. Wohl (Eds.), Treatise on geomorphology (Vol. 9, pp. 137-162). San Diego, CA: Academic Press. https://doi.org/10.1016/B978-0-12-374739-6.00235-9

Yokokawa, M., Hasegawa, K., Kanbayashi, S., \& Endo, N. (2010). Formative conditions and sedimentary structures of sandy 3D antidunes: An application of the gravel step-pool model to fine-grained sand in an experimental flume. Earth Surface Processes and Landforms, 35(14), 1720-1729. https://doi.org/10.1002/esp.2069

Yokokawa, M., Takahashi, Y., Yamamura, H., Kishima, Y., Parker, G., \& Izumi, N. (2011). Phase diagram for antidunes and cyclic steps based on suspension index, non-dimensional Chezy resistance coefficient and Froude number, In Proceedings of the International Association for Hydro-Environment Engineering and Research, 7th Symposium on River, Coastal and Estuarine Morphodynamics (RCEM 2011) (pp. 1789-1794).

Yokokawa, M., Tsuji, A., Kishimoto, K., Mizokami, Y., Murokawa, T., Muraoka, S., \& Naruse, H. (2011). Bedform Existence Diagrams for Open Channel Flow: Light Weight Plastic Versus Quartz. San Francisco, CA: American Geophysical Union. 